Journal of Applied Fluid Mechanics, Vol. 14, No. 6, pp. 1851-1868, 2021. Available online at www.jafmonline.net, ISSN 1735-3572, EISSN 1735-3645. https://doi.org/10.47176/jafm.14.06.32639

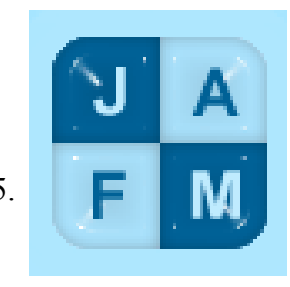

\title{
Characterization of Biogas-Syngas Turbulent MILD Combustion in the Jet in Hot Co-Flow Burner
}

\author{
O. Benbouaziz ${ }^{1}$, A. Mameri ${ }^{1 \dagger}$, A. Hadef $^{1}$ and Z. Aouachria ${ }^{2}$ \\ ${ }^{1}$ Laboratory of Advanced Design and Modeling of Mechanical Systems and Thermo-Fluids \\ (CMASMTF), Department of Mechanical Engineering, FSSA, Oum el Bouaghi University, Algeria \\ ${ }^{2}$ Laboratory of Applied Energy Physics, Department of Physics, University Batna 1, Batna 05000, Algeria
}

$\dagger$ Corresponding Author Email: mameriabdelbaki@yahoo.fr

(Received January 30, 2021; accepted June 1, 2021)

\begin{abstract}
Moderate or Intense Low-oxygen Diluted (MILD) combustion is a promising technology with interesting properties such as high efficiency and zero-emission. The biogas-syngas mixture is also considered a promising new renewable biofuel with low emissions. This work aims to examine the effects of several parameters on the biogas-syngas flame structure and emissions under MILD conditions in the Jet in Hot Co flow (JHC) burner. The turbulence is modeled by the modified standard $\mathrm{k}-\varepsilon$ model; whereas combustion-turbulence interaction is handled by the Eddy Dissipation Concept (EDC) in conjunction with three detailed reaction mechanisms, namely: GRI-Mech 3.0, GRI-Mech 2.11, and DRM 2.11. Effects of biogas-syngas composition, temperature, and oxygen concentration in the hot co-flow and Reynolds number of the fuel jet have been elucidated. Results show that flame structure is more sensitive to the increase of hydrogen in syngas than that of methane in biogas. An increase of oxygen concentration or temperature in the co-flow stream leads to more NO formation whereas Reynolds number augmentation reduced them. Furthermore, NO species production is globally governed by the NNH route.
\end{abstract}

Keywords: Biofuels; Chemical mechanism; MILD combustion; Turbulent non-premixed combustion.

\section{NOMENCLATURE}

$\begin{array}{ll}\mathrm{Cp} & \text { specific heat } \\ \mathrm{k} & \text { turbulent kinetic energy } \\ \mathrm{P} & \text { pressure } \\ \mathrm{Pr} & \text { turbulent Prandtl number } \\ Q & \text { mass flow rate } \\ \mathrm{U} & \text { velocity } \\ \mathrm{T} & \text { temperature } \\ \mathrm{Y}_{\mathrm{i}} & \text { mass fraction of species } \mathrm{i} \\ \mathrm{X}_{\mathrm{i}} & \text { mole fraction of species } \mathrm{i} \\ \mathrm{Z} & \text { mixture fraction }\end{array}$

\section{INTRODUCTION}

The large and rapid development of human society has depleted energy sources throughout the last decades. Fossil fuels have been excessively consumed in human comfort and technology expansion. This led to unreasonable amounts of harmful emissions, especially by combustion. The researchers have been solicited for developing low emissions, high efficiencies, and fuel-saving combustion devices. Furthermore, to seek sustainable and renewable alternative energy sources

$\begin{array}{ll}\alpha & \text { thermal diffusivity } \\ \rho & \text { density } \\ \mu & \text { dynamic viscosity } \\ \varepsilon & \text { kinetic dissipation rate } \\ \xi & \text { length fraction of the fine-scale } \\ \tau & \text { residence chemical time scale } \\ \lambda & \text { thermal conductivity } \\ v & \text { kinetic viscosity } \\ \mu_{\mathrm{t}} & \text { turbulent viscosity } \\ \hbar & \text { specific enthalpy }\end{array}$

such as nuclear, solar, and biofuels (Lenzen 2008), (Solangi et al. 2011) and (Demirbas 2009). However, fossil fuels represent over $75 \%$ of the world's total energy supply (Chefurka 2007), Fig.1; this makes their substitution improbable shortly. On the other hand, significant concerns exist about combustion pollutant emissions (Cavaliere and de Joannon 2004), such as $\mathrm{NOx}, \mathrm{CO}, \mathrm{CO}_{2}$, and soot, which have a significant impact on the environment. The immediate solution for the problem is optimization on combustion modes, devices and fuels. In combustion process optimization context, to reduce 




Fig. 1. Global energy consumption by source.

NOx and CO emissions, new technologies suggest reducing temperature peak and oxygen concentration. This can be operated by nitrogen dilution, (Lee et al. 2016) or by direct water steam injection (Benini et al. 2009) and by humidified exhaust recirculation (Taimoor et al. 2016). Whereas the most popular technique is called Moderate or Intense Low oxygen Dilution combustion (MILD) (Vasavan et al. 2018), High-Temperature Combustion Technology (HiCOT) (Cavaliere and de Joannon 2004) and (Niioka 2005), HighTemperature Air Combustion (HiTAC) (Niioka 1999) and (Gupta 2000) and flameless combustion (Wunning 2000). These technologies have a similar principle in using highly heated and diluted oxidizers. The MILD combustion mode has many advantages compared to the conventional one, namely: high reaction zone volume (Ito et al. 2002) and (Mörtberg et al. 2007), low-pressure oscillations which imply low noise (Wunning 2000), uniform temperature, and species distribution (Katsuki and Hasegawa 1998) and low pollutants emissions. Detailed features of the JHC burner operated under MILD combustion regime with three oxygen concentrations of $3 \%, 6 \%$ and $9 \%$ were investigated by (Dally et al. 2002). It has been found that increasing oxygen mass fraction leads to substantial variations in the structure of the flame with a temperature peak rise of $400 \mathrm{~K}$ and a threefold increase of both $\mathrm{NO}$ and $\mathrm{OH}$. (Christo and Dally 2005) explored turbulent non premixed methanehydrogen flames issuing from a JHC burner. The accuracy of several turbulence models, namely: standard $\mathrm{k}-\varepsilon$, realizable $\mathrm{k}-\varepsilon$, and RNG k- $\varepsilon$ was tested. Good agreement with experimental data was obtained by modifying the standard $\mathrm{k}-\varepsilon$ turbulence model constant $\mathrm{C}_{\varepsilon 1}$ from 1.4 to1.6. Also, accurate predictions were found when differential diffusion is considered. (Aminian et al. 2011) studied the influence of inlet turbulence energy on the prediction of mass fraction and mean temperature. MILD combustion in JHC burner is considered with varying oxygen levels in the hot co-flow steam. Results showed that turbulent kinetic energy has a substantial influence on the prediction of temperature and species mass fraction at both upstream and downstream of the burner. In turbulent non premixed MILD combustion of $\mathrm{CH}_{4}+\mathrm{H}_{2}$, (Mardani and Tabejamaat 2010) conducted a numerical study to investigate effects of hydrogen addition to the fuel on the flame structure. Two coflow oxygen fractions $(3 \%$ and $9 \%)$ and three fuel mixtures $\left(5 \% \mathrm{H}_{2}+95 \% \mathrm{CH}_{4}, \quad 10 \% \mathrm{H}_{2}+90 \mathrm{CH}_{4} \quad\right.$ and $20 \% \mathrm{H}_{2}+80 \mathrm{CH}_{4}$ ) were considered. The results revealed that when methane is enriched by hydrogen, reaction zone is reduced, mixture fraction, strain rate , and turbulent kinetic energy were all increased. Also, it was found that methane doping by hydrogen leads to important concentrations of $\mathrm{CH}_{2} \mathrm{O}, \mathrm{OH}$, and $\mathrm{HCO}$ which contributes respectively to enhanced mixture ignitability, reaction intensities, and heat release rate.

Pollution can be minimized by fuel selection; biofuels are an attractive choice in this context. Biogas and syngas have been proposed as clean and promising fuels (Holm-Nielsen et al. 2009), they have been used in fueling several applications, particularly IC engines, gas turbines, and furnaces (Chandra et al. 2011) and (Hosseini and Wahid 2013).

Biogas is obtained by the breakdown of organic material by methanogen (microorganisms) in the absence of oxygen (anaerobically). Biogas mainly consists of methane $\left(50 \%\right.$ to $\left.75 \% \mathrm{CH}_{4}\right)$ and carbon dioxide $\left(25 \%\right.$ to $50 \% \mathrm{CO}_{2}$ ). It may contain small amounts of hydrogen sulfide $\left(0.1 \%-0.5 \% \mathrm{H}_{2} \mathrm{~S}\right)$, Oxygen $\left(\mathrm{O}_{2} 0 \%-0.5 \%\right)$, hydrogen $\left(0 \%-1 \% \mathrm{H}_{2}\right)$ and nitrogen $\left(0 \%-10 \% \mathrm{~N}_{2}\right)$ (Verma et al. 2016). Carbon dioxide contained in biogas has a thermal effect as a diluent and a chemical one when it decomposes and reacts at elevated temperatures; also it reduces heat value (Park et al. 2003). Biogas low caloric value (LCV) problem can be recovered by hydrogen 
enrichment. (Mameri et al. 2018) examined the effect of several operating conditions, including hydrogen addition to biogas. The authors considered laminar opposed jets at atmospheric pressure. Results showed that enrichment of biogas by $\mathrm{H}_{2}$ enhances mixture heating value and increases the fuel reactiveness. (Leung and Wierzba 2008) investigated the stability of a diffusion flame for two biogas compositions $\left(60 \% \mathrm{CH}_{4}+40 \% \mathrm{CO}_{2}\right.$ and $\left.50 \% \mathrm{CH}_{4}+50 \% \mathrm{CO}_{2}\right)$ in a simple fuel jet with a coflowing air stream. It was found that with small amounts of hydrogen addition to the biogas, the flame becomes more stable in a large range of strain rates. The effect of hydrogen on the stability of biogas flames was also explored experimentally by (Zhen et al. 2013) in a non-premixed configuration. It was noticed that the variation of hydrogen volume from $5 \%$ to $10 \%$, improves significantly the biogas flame stability. Several studies reveal that hydrogen can be obtained from renewable sources such as syngas (Mameri et al. 2019) and (Zouagri et al. 2020). Syngas or synthesis gas is a combustible mixture produced by gasification (Maschio et al. 1994) and consists of important reactive species, mainly hydrogen $\mathrm{H}_{2}$ and carbon monoxide $\mathrm{CO}$ (Caudal 2013). Few researchers considered the $\mathrm{CH}_{4}$ / $\mathrm{CO}_{2} / \mathrm{H}_{2} / \mathrm{CO}$ or biogas-syngas mixture. (Mameri et al. 2019) investigated numerically laminar diffusion flame in counterflow configuration for many operating conditions of strain rate and ambient pressure (from $1 \mathrm{~atm}$ to $10 \mathrm{~atm}$ ) for seven mixtures of biogas syngas (by varying volumes of methane and hydrogen). It was found that the strain rate working interval is broadened by hydrogen volume increase in syngas. Whereas ambient pressure augmentation improved extinction temperature, and NO production, and reduced strain rate operating interval. It has been also noticed that the most important path for $\mathrm{NO}$ production is the $\mathrm{NO}_{2}$ route. The biogas-syngas flame structure and emissions were also considered by (Zouagri et al. 2020) in a numerical investigation. Volumes of methane and hydrogen were varied; whereas, the strain rate and pressure were kept constant. The authors found that flame characteristics are highly influenced by the composition of the mixture. Increasing pure fuels in the mixture showed an improvement in low heat value (LHV). The thickness of the reaction zone and maximum flame temperature were wider and production of $\mathrm{H}_{2} \mathrm{O}$ and $\mathrm{OH}$ species become higher. They also reported that NO production was related to the volume of methane in the mixture.

To obtain clean and efficient combustion, the interesting way of optimization was the use of MILD combustion of biofuels. Few studies investigated this topic, (Mameri et al. 2018) numerically studied the MILD combustion of the laminar 1D non-premixed flame of biogas. The authors found that the $\mathrm{CO}_{2}$ chemical effect reduces flame temperature, $\mathrm{NO}$ and $\mathrm{OH}$ species production. (Hosseini et al. 2015) carried out an experimental and numerical investigation of biogas in a cylindrical combustion chamber of a gas turbine under MILD combustion. It was found that the temperature in the chamber was uniform and pollutants emission were very low than conventional combustion. The increase of oxygen concentration in the oxidizer stream led to an efficiency increase. MILD combustion of biogas in a furnace was experimentally investigated by (Colorado et al. 2010). Results showed that emissions such as NOx and $\mathrm{CO}$ were very low with a large reaction zone and nearly constant temperature field in the furnace. (Mahmoudi et al. 2013) studied numerically and experimentally stabilization and lift-off height of turbulent diffusion flame of biogas in JHC burner. Results showed that adding hydrogen to the mixture increased significantly the lift-off height. (Sahin 2019) conducted a numerical study regarding biogas flame under the MILD regime. The influence of many operative conditions such as oxygen concentration in oxidizer stream and fuel composition has been undertaken. They revealed that when reducing oxygen concentration, $\mathrm{NOx}$ and $\mathrm{CO}$ levels are nearly zero. Also, they found that some biogas compositions are unaffected by the thermal field. (Huang et al. 2014b) explored numerically the effect of fuel types (biogas and hydrogen) and pressure on MILD combustion. Their results indicated that an augmentation in pressure increases the ignition delay of syngas mixture which is a consequence of the $\mathrm{OH}$ mole fraction decrease in the mixture when pressure increases. (Huang et al. 2014a) examined the importance of syngas jet velocity in the MILD combustion regime. The results revealed that an increase in fuel jet velocity leads to a good mixing between oxidizer and fuel; which contributes to lowering the temperature, uniformizing thermal field, and reducing NOx emissions.

The authors found that the $\mathrm{N}_{2} \mathrm{O}$ intermediate path is the main source of NOx production in syngas under MILD combustion. (Mardani and Karimi Motaalegh Mahalegi 2019) investigated hydrogen addition effect on methane and syngas under MILD combustion. It was noticed that increase of hydrogen enhances high-temperature regions for both fuels. Moreover, the syngas seems to be the better choice in achieving MILD combustion. Recently, (Chinnici et al. 2020) conducted a numerical and experimental study on syngas flame stability under the MILD regime by varying the $\mathrm{H}_{2} / \mathrm{CO}$ ratio. The results indicated that there is no significant influence when changing fuel composition on emissions, thermal efficiency, and temperature field. They also found that pollutant emissions such as NOx and $\mathrm{CO}$ are almost non-existent.

It is interesting to combine all these features mentioned above to improve the combustion process. This can be achieved by using the MILD combustion technique which is highly suitable for application with low calorific fuels (Chinnici et al. 2020), (Saha et al. 2017), and (Sabia et al. 2019). Moreover, hydrogen can be obtained from syngas, as it contains important amounts of hydrogen (Zouagri et al. 2020) and (Mameri et al. 2019). The objective of this study is to elucidate the MILD turbulent combustion of biogas-syngas mixture in a JHC burner. Effects of the volume of methane in biogas, hydrogen in syngas, oxygen concentration, the temperature of oxidizer stream, and velocity of the fuel jet are all depicted. 
O. Benbouaziz et al. / JAFM, Vol. 14, No. 6, pp. 1851-1868, 2021.

\section{GEOMETRY AND MATHEMATICAL MODELS}

\subsection{Validation burner configuration}

The JHC configuration of (Dally et al. 2002) is adopted in this work, Fig. 2. The authors investigated MILD combustion by injecting a fuel jet into a hot co-flow. The fuel, composed of a mixture of $\mathrm{CH}_{4}$ and $\mathrm{H}_{2}$ (1:1 volume), is issued through a pipe of a diameter $D_{\text {jet }}=2.25 \mathrm{~mm}$. Fuel is injected with a mass flowrate $Q_{j e t}=0.0045 \mathrm{~kg} / \mathrm{s}$ and a Reynolds number of approximately 10000 . The co-flow is formed by an annular channel of a diameter $D_{\mathrm{cf}}=82 \mathrm{~mm}$; which, surrounds the fuel jet and provides hot combustion products $\left(\mathrm{O}_{2}, \mathrm{CO}_{2}, \mathrm{H}_{2} \mathrm{O}\right.$, and $\left.\mathrm{N}_{2}\right)$ with a velocity $\mathrm{v}_{\mathrm{cf}}=3.2 \mathrm{~m} / \mathrm{s}$. Oxygen volume is varied from $3 \%$ to $9 \%$ with a constant temperature of $\mathrm{T}_{\mathrm{cf}}=1300 \mathrm{~K}$. The burner is completely installed in a wind tunnel which provides a cold mixture of air $\left(23 \% \mathrm{O}_{2}\right.$ and $\left.79 \% \mathrm{~N}_{2}\right)$ with a constant temperature of $305 \mathrm{~K}$.

\subsection{Governing equations}

In the present work, the following set of governing equations are numerically solved:

Continuity equation:

$$
\frac{\partial \rho}{\partial t}+\frac{\partial}{\partial x_{j}}\left(\rho U_{j}\right)=0
$$

Momentum conservation equation :

$$
\begin{aligned}
& \frac{\partial}{\partial t}\left(\rho U_{i}\right)+\frac{\partial}{\partial x_{j}}\left(\rho U_{i} U_{j}\right)= \\
& -\frac{\partial p}{\partial x_{i}}+\frac{\partial}{\partial x_{j}}\left(\tau_{i j}-\rho U_{i}^{\prime \prime} U_{j}^{\prime \prime}\right)
\end{aligned}
$$

Energy equation :

$$
\begin{aligned}
& \frac{\partial}{\partial t}(\rho \hbar)+\frac{\partial}{\partial x_{j}}\left(\rho \hbar U_{j}\right)= \\
& \frac{\partial}{\partial x_{j}}\left(\rho \alpha \frac{\partial \hbar}{\partial x_{j}}-\rho \hbar^{\prime \prime} U_{j}^{\prime \prime}\right)-\frac{\partial}{\partial x_{j}}\left(q_{r j}\right)+S_{h c}
\end{aligned}
$$

The term $-\rho h^{\prime \prime} U_{j}^{\prime \prime}=\frac{\mu_{t}}{P r_{t}} \frac{\partial h}{\partial x_{j}}$ is modeled by the turbulent heat flux, where $\operatorname{Pr}_{\mathrm{t}}$ is the turbulent Prandtl number.

Species conservation equation

$$
\begin{aligned}
& \frac{\partial}{\partial t}\left(\rho Y_{k}\right)+\frac{\partial}{\partial x_{j}}\left(\rho Y_{k} U_{j}\right)= \\
& \frac{\partial}{\partial x_{j}}\left(\left(\rho D_{m, k}+\frac{\mu_{t}}{S c_{t}}\right) \frac{\partial Y_{k}}{\partial x_{j}}\right)+\varpi_{s}
\end{aligned}
$$

In Eqs. (1) to (4), $U$ is the flow velocity, $\rho$ is the mixture density and $\mathrm{P}$ is the working pressure, $\hbar$ is the specific enthalpy, $\alpha$ is the mixture thermal diffusivity, $q_{r}$ the radiative heat loss term, and $S_{h c}$ is the combustion source term. $Y_{k}$ is the species $k$ mass fraction, $D_{m, k}$ is the species $k$ molecular diffusion coefficient in the mixture, and $S c_{t}$ is the turbulence Schmidt number.

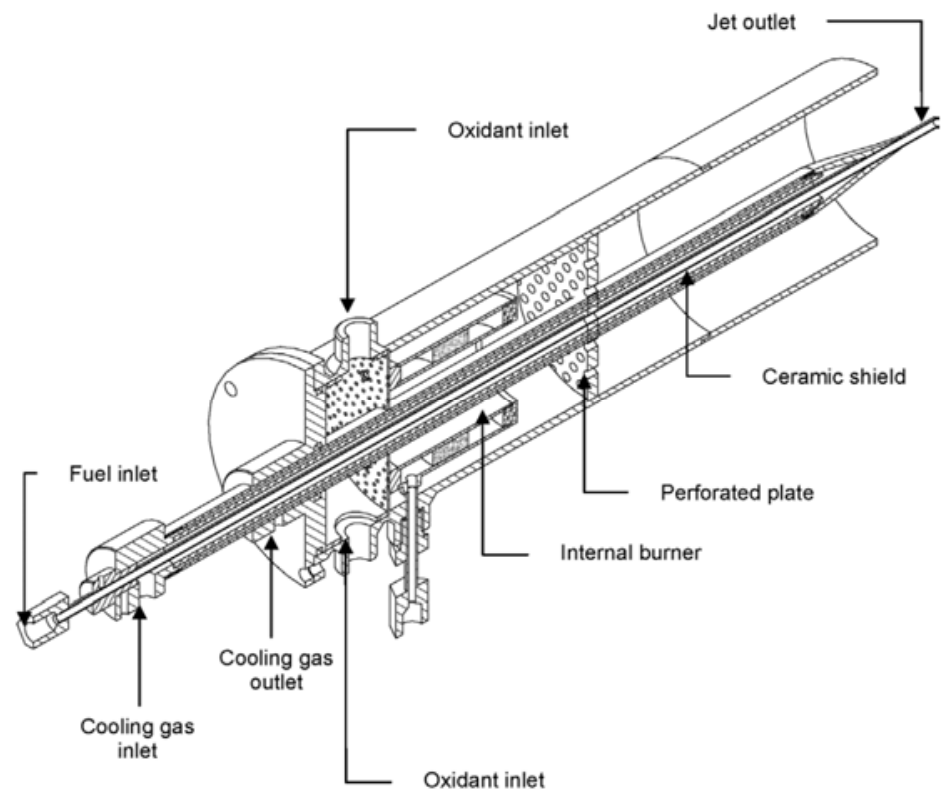

Fig. 2. JHC burner of (Dally et al. 2002). 


\subsection{Turbulence Models}

In the current study, several turbulence models capability has been examined, namely: Realizable k$\varepsilon$ (Shih et al. 1994), SST k- $\omega$ (Menter 1994) and modified standard k- $\varepsilon$. The standard $\mathrm{k}-\varepsilon$ model is based on solving transport equations of turbulence kinetic energy $k$ and its dissipation rate $\varepsilon$ given by:

$$
\begin{aligned}
& \frac{\partial}{\partial t}(\rho k)+\frac{\partial}{\partial x_{j}}\left(\rho k U_{j}\right)= \\
& \frac{\partial}{\partial x_{j}}\left(\left(\mu+\frac{\mu_{t}}{\sigma_{t}}\right) \frac{\partial k}{\partial x_{j}}\right)+G_{k}-\rho \varepsilon \\
& \frac{\partial}{\partial t}(\rho \varepsilon)+\frac{\partial}{\partial x_{j}}\left(\rho \varepsilon U_{j}\right)= \\
& \frac{\partial}{\partial x_{j}}\left(\left(\mu+\frac{\mu_{t}}{\sigma_{\varepsilon}}\right) \frac{\partial \varepsilon}{\partial x_{j}}\right)+C_{1 \varepsilon} \rho \frac{\varepsilon}{k} G_{k}-C_{2 \varepsilon} \rho \frac{\varepsilon^{2}}{k}
\end{aligned}
$$

Where $\mathrm{G}_{\mathrm{k}}$ is the production rate of turbulence kinetic energy. $C_{1 \varepsilon}, C_{2 \varepsilon}, \partial \varepsilon$ and $\sigma_{\varepsilon}$ are model constants. Turbulent viscosity $\mu_{t}$ is computed by $\mu_{t}=\rho C_{\mu} \frac{\varepsilon^{2}}{k}$.

According to the previous simulation works on the $\mathrm{JHC}$ for non-premixed hydrogen methane flame (Christo and Dally 2005), $\mathrm{C}_{1 \varepsilon}$ in equation (6) is adjusted from 1.44 to 1.6 to improve the prediction accuracy of the standard k- $\varepsilon$ model (Frassoldati et al. 2010).

Table 1 Constants of the standard k- $\varepsilon$ model.

\begin{tabular}{|c|c|c|c|c|}
\hline$C_{1 \varepsilon}$ & $C_{2 \varepsilon}$ & $C_{\mu}$ & $\sigma_{t}$ & $\sigma_{\varepsilon}$ \\
\hline 1.44 changed to 1.6 & 1.92 & 0.09 & 1.0 & 1.3 \\
\hline
\end{tabular}

\subsection{Combustion Modelisation}

The interaction between turbulence and combustion is key in turbulent combustion simulation. In MILD turbulent combustion, the EDC model (Magnussen 1981), which is an enhanced version of the Eddy Break UP model EBU (Spalding 1977), has shown its performance. Several studies (Frassoldati et al. 2010), (Galletti et al. 2009) and (Galletti et al. 2007) have shown that the EDC model provides satisfactory prediction in MILD turbulent combustion. In this model, it is presumed that the reaction occurs in fine scales $\xi$ in a time scale. Both of $\xi$ and $\tau$ are given in term of turbulent properties by:

$$
\begin{aligned}
& \xi=C_{\xi}\left(\frac{v \varepsilon}{k^{2}}\right)^{\frac{1}{4}} \\
& \tau=C_{\tau}\left(\frac{v}{\varepsilon}\right)^{\frac{1}{2}}
\end{aligned}
$$

Where $v$ is the kinetic viscosity, $C_{\xi}$ and $C_{\tau}$ are model constants having respectively the values 2.1377 and 0.4038 . For each species $k$, the chemistry source term $\widetilde{\omega_{s}}$ is calculated by:

$$
\varpi_{s}=-\frac{\rho \xi^{2}}{\tau\left(1-\xi^{3}\right)}\left(Y_{k}-Y_{k}^{*}\right)
$$

The term $Y_{k}^{*}$ is the species $k$ mass fraction in the fine structure and $Y_{k}$ is the mean mass fraction of species $k$ between the fine structure and surrounding fluid.

\subsection{Geometry and numerical details}

The axial symmetry of the JHC geometry simplifies the problem to a two-dimensional axisymmetric configuration. According to (Parente et al. 2016), a two-dimensional axisymmetric simulation could be used instead of a tridimensional one to reduce computational effort and to predict accurately as a tridimensional simulation. Figure 3 shows the axisymmetric domain of the JHC burner with a computational grid with about 25000 cells. The solution-grid independence was verified by using three different meshes (coarse, medium, and fine). Detailed comparisons will be discussed in the next section. Numerical simulations were conducted by using the Fluent ANSYS CFD software based on the finite-volume method (FVM). The SIMPLE algorithm (Kaiser 1990) was employed to solve the pressure-velocity coupling, a second-order upwind scheme was applied for all the governing equations. Residuals for all equations were kept less than $10^{-5}$ as a convergence criterion.

To have accurate prediction using the EDC model, it is crucial to tune boundary conditions especially the mean kinetic turbulent energy (Wang et al. 2011c), (Mardani et al. 2010) and (Christo and Dally 2005). Consequently, the mean turbulent kinetic energy of the fuel stream and hot co-flow are taken as $60 \mathrm{~m}^{2} / \mathrm{s}^{2}$ and $1.8 \mathrm{~m}^{2} / \mathrm{s}^{2}$, respectively. Moreover, according to Parente et al (Parente et al. 2016), the EDC model time scale constant $C_{\tau}$ in eq. (8) could be adjusted from 0.04082 to 0.82 to correct the overestimation in the JHC flame temperature. Lewandowski et al. (Lewandowski and Ertesvåg, 2018a) compared the EDC model modified constants with the original one, it was concluded that the variable reacting fraction approach gives better estimation of the temperature field and lift-off height. In a recent paper, Lewandowski et al. (2020c) proposed a new method for model constants computations in MILD regime. Making the model more general, the constants are function of local turbulence Reynolds and Damköhler numbers. In a more recent paper, the authors (Lewandowski, Li, et al. 2020b) applied the newly proposed model to twelve flames covering Adelaide and Delft burners in MILD regime. A broad range of operating conditions was covered and promoting results were obtained. Thermal radiation was neglected according to (Christo and Dally 2005), it was observed that thermal radiation didn't 


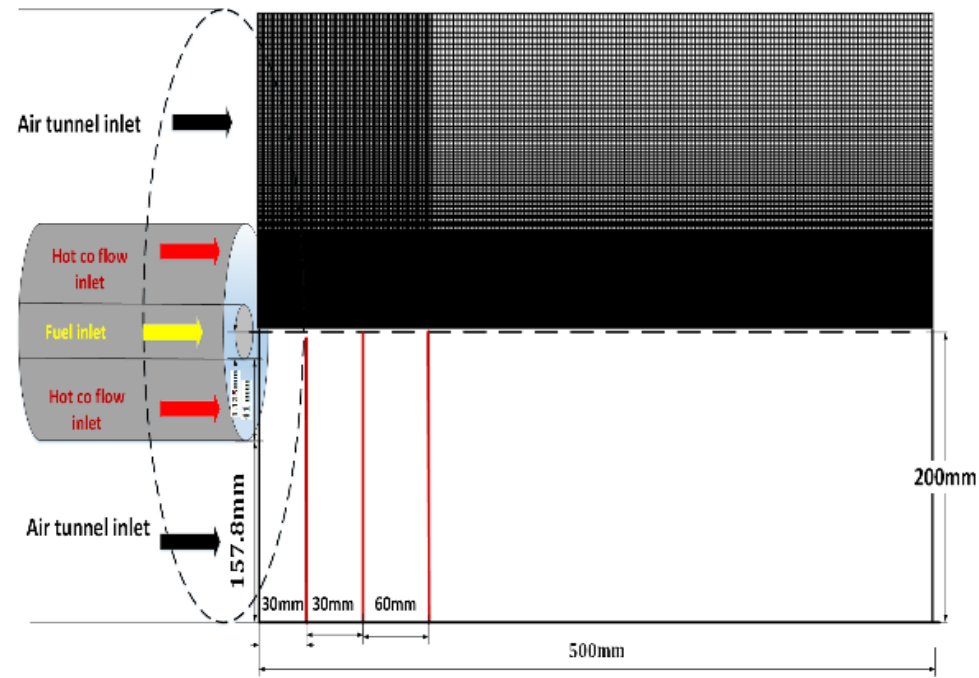

Fig. 3. The JHC burner and computational domain meshing.

have any noticeable effect on the results.

Chemistry kinetics was described by three detailed mechanisms, namely: GRI-Mech 3.0 (Smith 1999), which is composed of 53 species involving a total of 325 reversible reactions, GRI-Mech 2.11 (Bowman et al. 1995), with 53 species and 277 reversible reaction and DRM-22 (Kazakov and Frenklach 1994), a reduced version of the full chemical mechanism GRI-Mech 1.2. According to the previous works of (Mardani et al. 2010), (Zhang et al. 2015), (Wang et al. 2015a; 2015b) and (Kim et al. 2005), the GRI-Mech 3.0 overpredict NO levels comparatively to GRI-Mech 2.11.

\subsection{Mechanisms of NO production}

Four important routes of nitric oxide $\mathrm{NO}$ are considered in this study, namely: thermal or Zeldovich mechanism (Turns 1996), prompt or Fenimore (Turns 1996) path, $\mathrm{N}_{2} \mathrm{O}$ intermediate mechanism, and NNH mechanism (Turns, 1996)(Shabanian et al. 2011). In the thermal mechanism, $\mathrm{NO}$ is formed by breaking the triple bond of $\mathrm{N}_{2}$ at high temperature $(>1700 \mathrm{~K})$ by $\mathrm{O}$ atoms to obtain $\mathrm{N}$ atom, which is oxidized to NO, by the following reactions:

$$
\begin{aligned}
& \mathrm{O}+\mathrm{N}_{2} \rightleftarrows \mathrm{NO}+\mathrm{N} \\
& \mathrm{N}+\mathrm{O}_{2} \rightleftarrows \mathrm{NO}+\mathrm{O} \\
& \mathrm{N}+\mathrm{OH} \rightleftarrows \mathrm{NO}+\mathrm{H}
\end{aligned}
$$

The reaction (10) requires high activation energy to occur; therefore, it has a very strong temperature dependence (Turns 1996). Prompt mechanism occurs when hydrocarbon radicals $\mathrm{CH}_{\mathrm{X}}$ (e.g. $\mathrm{CH}$, $\mathrm{CH}_{2}, \mathrm{CH}_{3} \ldots$ etc.) react with nitrogen $\mathrm{N}_{2}$ to form $\mathrm{HCN}$. Then, the latter is converted into NO through various intermediates. The $\mathrm{N}_{2} \mathrm{O}$ intermediate mechanism converts $\mathrm{N}_{2}$ to $\mathrm{N}_{2} \mathrm{O}$ by following three steps mechanism:

$\mathrm{O}+\mathrm{N}_{2}+\mathrm{M} \rightleftarrows \mathrm{N}_{2} \mathrm{O}+\mathrm{M}$

\section{$\mathrm{H}+\mathrm{N}_{2} \mathrm{O} \rightleftarrows \mathrm{NO}+\mathrm{NH}$}

$\mathrm{O}+\mathrm{N}_{2} \mathrm{O} \rightleftarrows \mathrm{NO}+\mathrm{NO}$

This mechanism becomes important in the case of fuel-lean and low-temperature conditions. The NNH mechanism forms $\mathrm{NO}$ by the transformation of $\mathrm{N}_{2}$ through intermediate reactions:

$\mathrm{N}_{2}+\mathrm{H} \rightleftarrows \mathrm{NNH}$

$\mathrm{NNH}+\mathrm{O} \rightleftarrows \mathrm{NH}+\mathrm{NO}$

Detailed reactions for each NO mechanism can be found in (Wang et al. 2015a) and (Shabanian et al. 2011).

To calculate NO production from a specific path, its main initiation reactions are disabled. For example, the thermal path is suppressed by deactivating the step $\mathrm{N}+\mathrm{NO}<=>\mathrm{N}_{2}+\mathrm{O}$ while the prompt one by disabling reactions $\mathrm{CH}+\mathrm{N}_{2}<=>\mathrm{NCN}+\mathrm{H}$ and $\mathrm{CN}+\mathrm{N}<=>\mathrm{C}+\mathrm{N}_{2}$. Then the difference between the full mechanism and the concerned one, in which the path is disabled, is computed, (Boussetla et al. 2021). This procedure is necessary as many NO production reactions are shared by different routes.

It should be also mentioned that only NO produced from the main jet flame is considered since the hot co-flow is obtained by simple heating and not from burned gases.

\section{RESULTS AND DISCUSSIONS}

Twenty numerical studied cases are presented in Tables 2 to 6 . The first three cases involve numerical procedure validation in $\mathrm{H}_{2} / \mathrm{CH}_{4}$ fuel mixture (Dally et al. 2002) followed by seven cases that investigate the effect of different $\mathrm{CH}_{4} / \mathrm{CO}_{2} / \mathrm{H}_{2} / \mathrm{CO}$ species concentration (cases 4 to 10). Then, three cases to investigate the effect of hot co-flow temperature (cases 11 to 13 ). The simulations 14 to 16 analyze Reynolds number of fuel inlet jet effect, and finally, cases 17 to 20 are dedicated to the effect of oxygen volume in the hot co-flow. 


\subsection{Grid independency study}

Several studies investigated the JHC burner, among them (Mardani and Tabejamaat 2010), (Frassoldati et al. 2010), (Wang et al. 2015a), (Mardani and Karimi Motaalegh Mahalegi 2019), (Wang et al. 2011c), (Jiang et al. 2018) and (Dai et al. 2018). In these studies, it was noticed that a grid of nearly 22000 nodes was sufficient to get mesh-solution independence. In this study, the grid independency test is achieved by using several meshes and variables, three of them are presented, namely those with 9000,36000 , and 45000 nodes. The results on dynamic, thermal, and species fields were respectively represented by velocity, temperature, and mixture fraction. Figure 4 shows the variation of the considered parameters in both axial and radial directions (at $\mathrm{x}=60 \mathrm{~mm}$ ). Both grids of 36000 and 45000 nodes give similar results which mean independence of the solution. The grid of 36000 nodes was considered for computations.
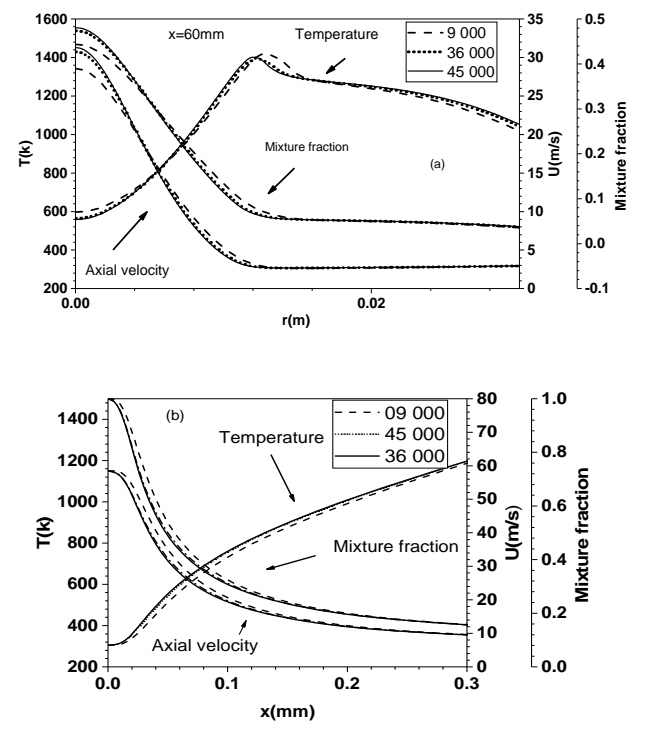

Fig. 4. Mesh independency for velocity, temperature, and mixture fraction.

\subsection{Validation of model and numerical method}

Currently, there is no experimental data on the biogas-syngas mixture in turbulent flames under MILD conditions. Therefore, experimental data of Dally et al (Dally et al. 2002) on $\mathrm{CH}_{4} / \mathrm{H}_{2}$ jet will be used for validation. Firstly, numerical simulation results are compared with experimental data in Fig.5 ( $a, b, c$ and d). Three cases that belong to oxygen mass fractions of $3 \%, 6 \%$, and $9 \%$ (cases 1 to 3 in Table 2) are compared in terms of mean temperature, oxygen mass fraction, and mixture fraction. Four stations $x=30 \mathrm{~mm}, \mathrm{x}=60 \mathrm{~mm}, \mathrm{x}=120 \mathrm{~mm}$ and $\mathrm{r}=0 \mathrm{~mm}$ (axial) were used. Generally, acceptable agreements between measurements and simulations for all test cases were observed. However, it is worth noting some disagreements in the peak and decay of the temperature profiles at the station $\mathrm{x}=120 \mathrm{~mm}$. This discrepancy is thought to be caused by the twodimensional axisymmetric approximation and also turbulent combustion and turbulence models (Mardani and Karimi Motaalegh Mahalegi, 2019) and (Aminian et al. 2012). It should be noticed that the flame above $100 \mathrm{~mm}$ from the nozzle is affected by the mixing with wind tunnel fresh air. Thus, the MILD regime appears to be more established below this height (Dally et al. 2002).

The temperature peak over-prediction problem might be the consequence of the EDC model constants optimization which was operated for conditions other than the MILD regime. Previous studies adjusted the EDC model constants to improve predictions in the MILD regime. As has been mentioned previously, the Lewandowski modification (Lewandowski et al. 2020c) was found to fit the best measurements, especially for temperature profile peaks (Lewandowski et al. 2020c). It can also be observed that accuracy of prediction, in both, mean temperature and oxygen mass fraction, increase for high levels of oxygen. Therefore, an oxygen mass fraction of $9 \%$ is selected in this study. Moreover, Fig. 5 (d) shows that computed mixture fraction at the four stations $\mathrm{x}=30$ $\mathrm{mm}, 60 \mathrm{~mm}, 120 \mathrm{~mm}$ and axial direction $(\mathrm{r}=0 \mathrm{~mm})$ can accurately predict jet spreading and mixing. Which impacts significantly mean temperature and mass fraction results. The Bilger's mixture fraction was calculated by (Bilger and Starner 2006):

$z=\frac{\left[\frac{2\left(Z_{C}-Z_{C . o x}\right)}{W_{c}}+\frac{2\left(Z_{H}-Z_{H . o x}\right)}{2 W_{H}}-\frac{2\left(Z_{O}-Z_{O . o x}\right)}{W_{O}}\right]}{\left[\frac{2\left(Z_{C . f u}-Z_{C . o x}\right)}{W_{c}}+\frac{2\left(Z_{H . f u}-Z_{H . o x}\right)}{2 W_{H}}-\frac{2\left(Z_{O . f u}-Z_{O . o x}\right)}{W_{O}}\right]}$

Where $Z_{j}$ is the mass fractions of elements (e.g. $\mathrm{C}, \mathrm{H}, \mathrm{O})$ which can be obtained from the mass fractions of species containing these elements: $Z_{j}=\sum_{i=1}^{N} \frac{\Phi_{i j} W_{j}}{M W_{i}} Y_{i}$, where $\Phi_{i j}$ is the $j$ atoms number in species $i \mathrm{~W} j$ and MW $i$ are respectively the atomic weight of element $j$ and molecular weight of species $i$. The subscripts $o x$ and $f u$ refer to fuel and air streams, respectively.

Secondly, a comparison between simulated contours of $\mathrm{OH}$ and experimental image of (Dally et al. 2002) for three flames HM1, HM2, and HM3 (cases 1 to 3 in Table 3) is shown by Fig. 6. It can be seen that increasing oxygen in the hot co-flow stream leads to a brighter flame. Specifically, the MILD region can be observed where the flame is not visible $(x<100 \mathrm{~mm})$. Numerical results also showed that $\mathrm{OH}$ lines can predict flame dimensions with good accuracy.

\subsection{Biogas-syngas mixture composition effect}

In this section, molar fractions of the fuel compounds (biogas-syngas) are varied according to Eq. (19). Firstly, in biogas, $\mathrm{CO}_{2}$ is substituted by methane so that the molar fraction of methane ranges from 
O. Benbouaziz et al. / JAFM, Vol. 14, No. 6, pp. 1851-1868, 2021.
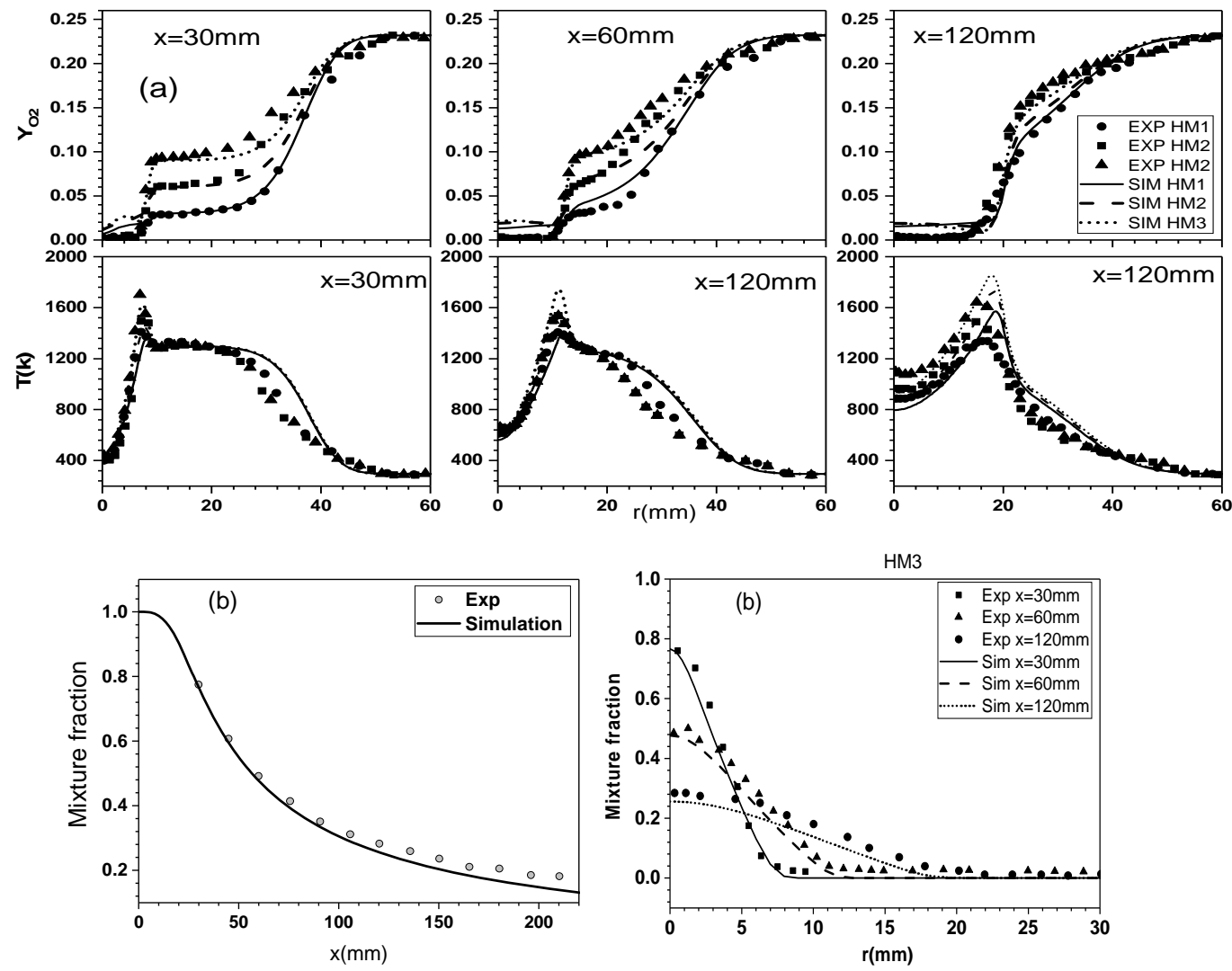

Fig. 5. Comparison between simulations and experiments at $x=30,60$ and $120 \mathrm{~mm}$ for three $\mathrm{JHC}$ flames of Dally et al. (a), and mixture fractions for HM3 (b).

Table 2 Validation compositions.

\begin{tabular}{|c|c|c|c|c|c|c|}
\hline \multirow{2}{*}{$\mathrm{N}^{\circ}$} & \multirow{2}{*}{ ID } & \multicolumn{4}{|c|}{ Hot Oxidizer mass fraction } & \multirow{2}{*}{ Chemical mechanism } \\
\hline & & $\mathrm{O}_{2}$ & $\mathrm{~N}_{2}$ & $\mathrm{H}_{2} \mathrm{O}$ & $\mathrm{CO}_{2}$ & \\
\hline 1 & HM1 & 0.03 & 0.85 & 0.065 & 0.055 & Gri 2.11 \\
\hline 2 & HM2 & 0.06 & 0.82 & 0.065 & 0.055 & Gri 2.11 \\
\hline 3 & HM3 & 0.09 & 0.79 & 0.065 & 0.055 & Gri2.11,3.0, DRM-22 \\
\hline Fuel : $\mathrm{Y}_{\mathrm{H} 2}=0.111, \mathrm{Y}_{\mathrm{CH} 4}=0.889$. & $\mathrm{Y}_{\mathrm{H} 2}=0$ & $\begin{array}{l}11, Y_{C} \\
\text { numb }\end{array}$ & $\begin{array}{r}0.889 \\
1000\end{array}$ & & & \\
\hline
\end{tabular}

Table 3 Fuel composition variation.

\begin{tabular}{|c|c|c|c|c|c|c|}
\hline \multirow{2}{*}{$\mathrm{N}^{\circ}$} & \multirow{2}{*}{$\mathrm{ID}$} & \multicolumn{4}{|c|}{ Fuel composition mole fractions $\mathrm{X}_{\mathrm{i}}$} & \multirow{2}{*}{$Z_{\text {st }}$} \\
\cline { 3 - 6 } & & $\mathrm{CH}_{4}$ & $\mathrm{CO}_{2}$ & $\mathrm{H}_{2}$ & $\mathrm{CO}$ & \\
\hline 4 & $\mathrm{~B} 00 \mathrm{~S} 25$ & 0.00 & 0.50 & 0.25 & 0.25 & 0.2703 \\
\hline 5 & $\mathrm{~B} 10 \mathrm{~S} 25$ & 0.10 & 0.40 & 0.25 & 0.25 & 0.1563 \\
\hline 6 & B50S25 & 0.50 & 0.00 & 0.25 & 0.25 & 0.0359 \\
\hline 7 & B25S25 & 0.25 & 0.25 & 0.25 & 0.25 & 0.0844 \\
\hline 8 & B25S00 & 0.25 & 0.25 & 0.00 & 0.50 & 0.1078 \\
\hline 9 & B25S10 & 0.25 & 0.25 & 0.10 & 0.40 & 0.0984 \\
\hline 10 & B25S50 & 0.25 & 0.25 & 0.50 & 0.00 & 0.0625 \\
\hline
\end{tabular}

Oxidizer: $\mathrm{X}_{\mathrm{O} 2}=0.09, \mathrm{X}_{\mathrm{H} 2 \mathrm{O}}=0.065, \mathrm{X}_{\mathrm{CO} 2}=0.065, \mathrm{X}_{\mathrm{N} 2}=0.79$. Fuel velocity: $58.75 \mathrm{~m} / \mathrm{s}$. 


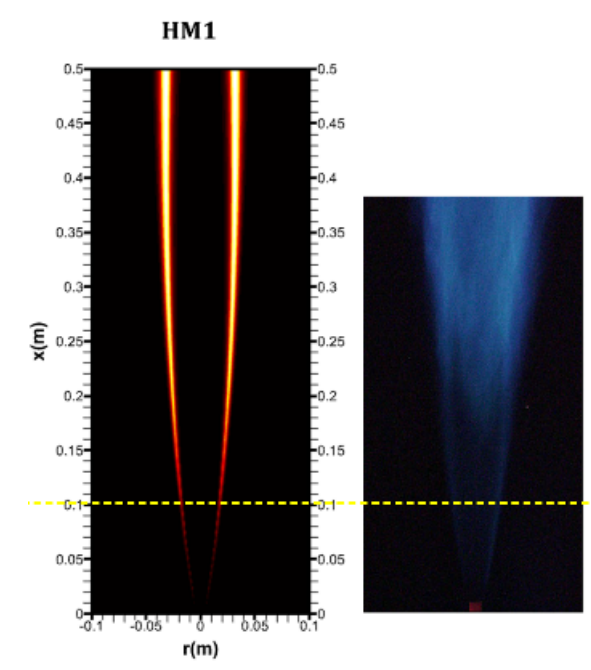

HM2
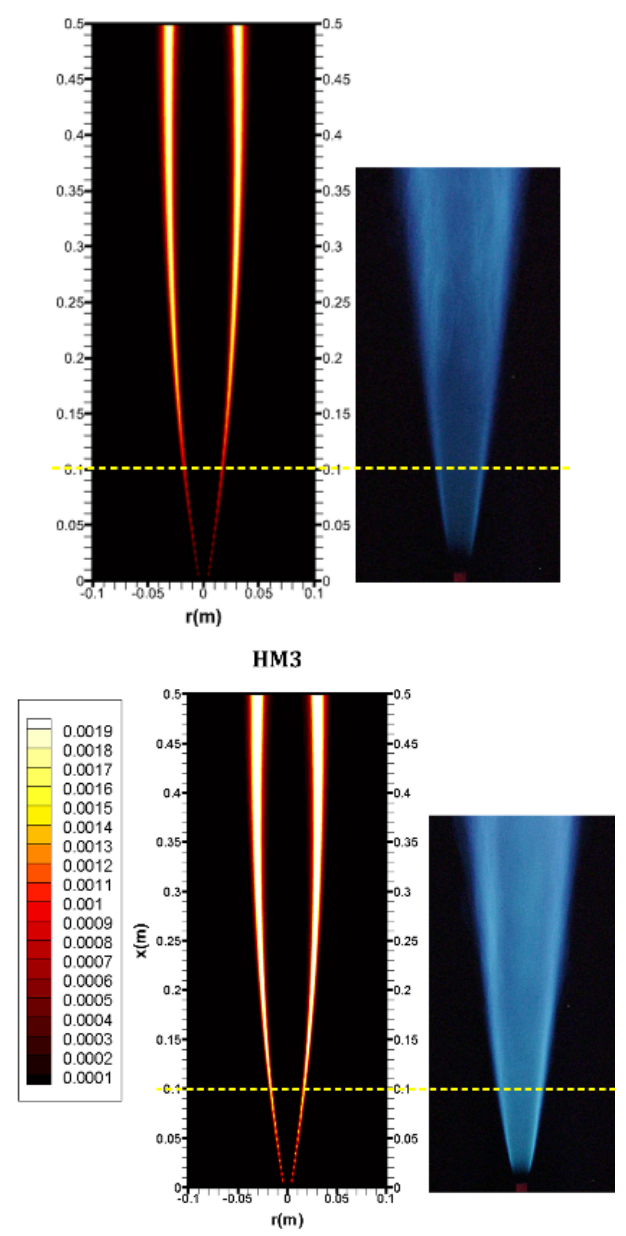

Fig. 6. Comparisons between JHC flame images and simulated $\mathrm{OH}$ molar fraction contours in the experiment of Dally et al (Dally et al. 2002).

$\mathrm{X}_{\mathrm{CH} 4}=0$ to 0.5 , that of carbon monoxide from $\mathrm{X}_{\mathrm{CO} 2}=0.5$ to 0 , and they sum to 0.5 ; while keeping hydrogen and $\mathrm{CO}$ mole fractions constant
$\left(\mathrm{X}_{\mathrm{H} 2}=\mathrm{X}_{\mathrm{CO}}=0.25\right)$. Secondly, in syngas, the same procedure is repeated for hydrogen and carbon monoxide mole fractions; while keeping methane and carbon dioxide mole fractions constant (Table 3).

$$
\delta \mathrm{CH}_{4}+(0.5-\delta) \mathrm{CO}_{2}+\beta \mathrm{H}_{2}+(0.5-\beta) \mathrm{CO}
$$

To present results, the station $\mathrm{x}=60 \mathrm{~mm}$ is selected since it warrants MILD regime combustion (combustion temperature increase didn't exceed mixture autoignition one). Figure 7 (a) shows the variation of flame temperature, oxygen mass fraction, and mixture fraction $z$, which is computed by using Bilger's formula (Bilger and Starner 2006) different compositions (BXS25, $\mathrm{X}_{\mathrm{CH} 4}=0$ to 0.5 and $\mathrm{X}_{\mathrm{CO} 2}=0.5$ to 0 ) were considered. It can be observed that for all compositions, mean temperature profiles exhibit the same trends.
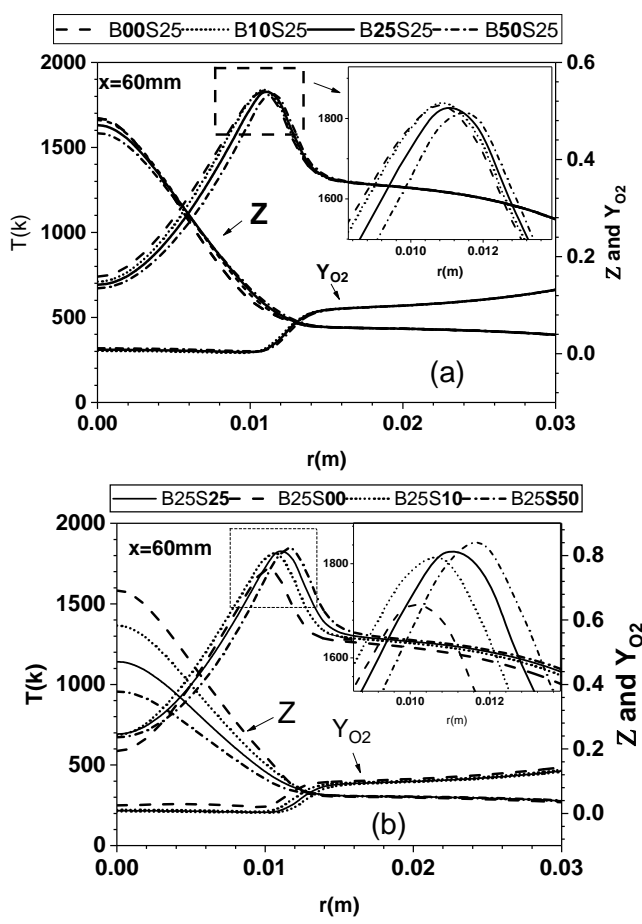

Fig. 7. Radial profiles of temperature, mixture fraction and $Y_{02}$ at $x=60 \mathrm{~mm}$ for :(a) cases 4 to 7 and (b) cases 7 to 10, of Table 3 .

They start from the lowest value on the axis of symmetry and increase to reach the maximum value at the mixing region between fuel and hot co-flow jet. Then they decrease to reach the temperature of hot co-flow $1300 \mathrm{~K}$ and then tunnel air $\mathrm{T}=300 \mathrm{~K}$. It has been observed that when methane mole fraction varies from 0 to 0.5 , the maximum temperature slightly decreases from $1833 \mathrm{~K}$ to $1815 \mathrm{~K}$ (less than $1 \%$ ), and its location shifts from $10.7 \mathrm{~mm}$ to $11.4 \mathrm{~mm}$ in the radial direction. This can be firstly explained by the trivial mixture fraction variations from one composition to another. Secondly, the lack of oxygen in MILD combustion makes the mixture locally rich 
which explains the slight decrease of temperature with methane addition. On the other hand, Fig.7 (b) shows that when hydrogen is added to syngas, maximum combustion temperature at this location $(\mathrm{x}=60 \mathrm{~mm})$ increases from $1712 \mathrm{~K}$ for $\mathrm{B} 25 \mathrm{~S} 00$ to $1845 \mathrm{~K}$ for B25S50 (nearly 7\%). The maximum flame location shifts from $10.1 \mathrm{~mm}$ to $11.6 \mathrm{~mm}$ in the radial direction. For this case, the mixture fraction varies significantly from one composition to another, this significate that mixing is enhanced since hydrogen is a very diffuse species.

Consumption of different fuel mixture compounds is shown by Fig. 8 in the radial direction at station $\mathrm{x}=60 \mathrm{~mm}$. Both cases of methane and hydrogen addition are respectively presented by Fig. 8(a) and (b). Radial profiles show that consumption is enhanced by the increase of fuel compounds volume at the injection. All compounds vanish at $r=12.5 \mathrm{~mm}$ which indicates nearly the maximum flame temperature position. The exception is made for $\mathrm{CO}$ species which is injected and produced by $\mathrm{CO}_{2}$ decomposition. It can be seen from the $\mathrm{CO}$ profile slope that $\mathrm{CO}$ is consumed, then produced at the flame front, and finally recombined to $\mathrm{CO}_{2}$ after the flame front.

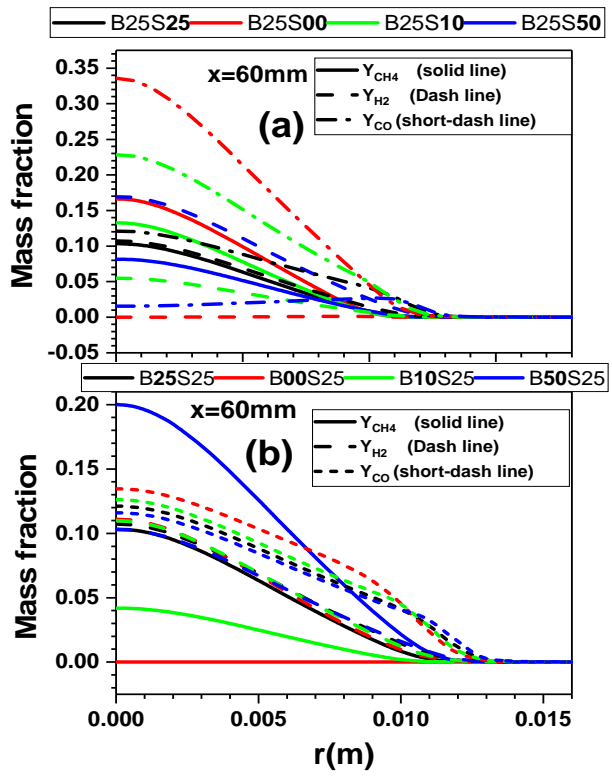

Fig. 8. Radial profiles of $\mathrm{Y}_{\mathrm{CH} 4}, \mathrm{Y}_{\mathrm{H} 2}$, and $\mathrm{Y}_{\mathrm{O} 2}$ at $x=60 \mathrm{~mm}$ for cases 4 to 10 of Table 3 .

In Fig. 9 methane and hydrogen effect on radial profiles (at $\mathrm{x}=60 \mathrm{~mm}$ ) of both intermediate species $\mathrm{OH}$ and $\mathrm{CH}_{2} \mathrm{O}$ mass fraction have been depicted (cases 4 to 10). The $\mathrm{OH}$ species is an important indicator of heat release, fuel consumption, and mixture reactivity. It attacks methane through the reaction $\mathrm{OH}+\mathrm{CH}_{4} \rightleftarrows \mathrm{CH}_{3}+\mathrm{H}_{2} \mathrm{O}$. In addition, $\mathrm{CH}_{2} \mathrm{O}$ is considered an indicator of autoignition (Gordon et al. 2009). Consequently, it is important to examine these indicators to obtain a better understanding of the combustion structure of this biofuel mixture. It can be observed in Fig. 9 (a) that increasing the volume of methane in biogas (BXS25) is associated with a decrease in $\mathrm{OH}$ concentration and an increase in $\mathrm{CH}_{2} \mathrm{O}$ concentration. Which indicates an improvement of autoignition and a lack of heat release. Here $\mathrm{OH}$ is mainly produced from hydrogen which is kept constant in this case (BXS25), when $\mathrm{CH}_{4}$ increases it consumes $\mathrm{OH}$ for its depletion which explains the reduction of $\mathrm{OH}$ with augmentation of $\mathrm{CH}_{4}$. While $\mathrm{OH}$ mole fraction peaks at maximum flame temperature (Fig. 7), the $\mathrm{CH}_{2} \mathrm{O}$ is formed from axis and decreases since its formation completely depends on methane through the reactions $\mathrm{OH}+\mathrm{CH}_{4} \rightleftarrows \mathrm{CH}_{3}+\mathrm{H}_{2} \mathrm{O}$ and $\mathrm{CH}_{3}+\mathrm{O} \rightleftarrows \mathrm{CH}_{2} \mathrm{O}+\mathrm{H}$. When hydrogen is increased in syngas (B25SX) Fig. 9 (b), $\mathrm{OH}$ mole fraction values are very close to each other for different hydrogen volumes. In this case methane volume is constant which explains the slight variation of $\mathrm{OH}$ radical with a small shift in the increasing radial direction. Regarding the radial profiles of $\mathrm{CH}_{2} \mathrm{O}$, it can be seen that the same behavior of Fig. 9 (a) is conserved.
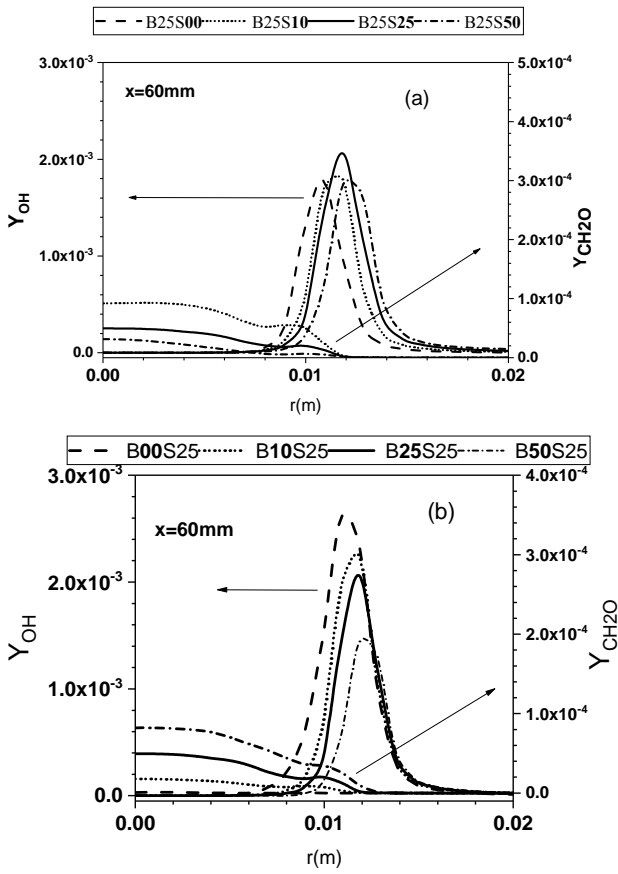

Fig. 9. Radial profiles of $Y_{\mathrm{OH}}$ and $\mathrm{Y}_{\mathrm{CH} 2 \mathrm{O}}$ at $\mathrm{x}=60$ $\mathrm{mm}$ for cases 4 to 10 of Table 3 .

Figure 10 displays temperature and $\mathrm{OH}$ mass fraction contours for cases 4 to 10 . The higher half of the figure represents two values of constant temperature lines namely: $1000 \mathrm{~K}$ and $2000 \mathrm{~K}$, whereas, the lower half shows iso-OH mass fraction $\mathrm{Y}_{\mathrm{OH}}=0.001$. It can be noticed that when increasing methane in biogas (BXS25), Fig. 10(a)), the iso-temperature lines expand upstream mostly in the radial direction and flame volume is increased which can be beneficial for processes involving flame volume such as radiation. Moreover, $\mathrm{OH}$ isolines move away from the axis. On the other hand, when hydrogen is added 
to syngas (B25SX, Fig. 10(b)), expansion is recorded in both directions especially for the isoline $2000 \mathrm{~K}$ in the axial direction. This behavior gives an idea about how hydrogen addition increases mixture reactivity and fixes flames lift stabilization issues. Relatively slight variations are presented for $\mathrm{OH}$ isoline.

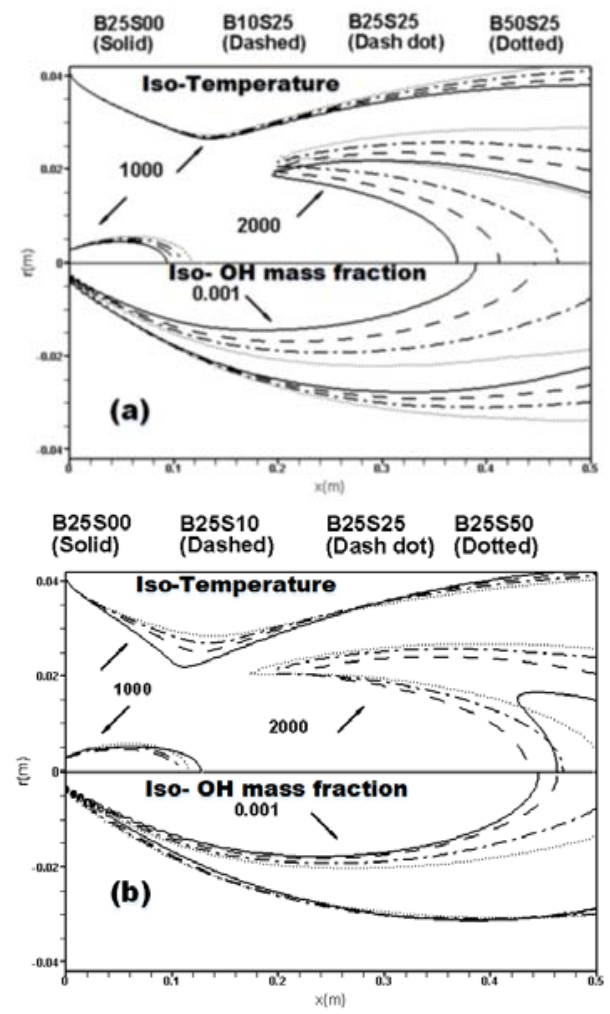

Fig. 10. Isolines of temperature (upper half) $\mathrm{Y}_{\mathrm{OH}}$ (lower half) for (a) cases 4 to 7 and (b) cases 7 to 10 of Table 3.

Figure 11 shows the mass fraction of combustion products namely: $\mathrm{Y}_{\mathrm{CO} 2}, \mathrm{Y}_{\mathrm{H} 2 \mathrm{O}}, \mathrm{Y}_{\mathrm{CO}}$, and $\mathrm{Y}_{\mathrm{NO}}$ in the radial direction at location $\mathrm{x}=60 \mathrm{~mm}$. It can be seen that when increasing methane volume in biogas, $\mathrm{H}_{2} \mathrm{O}$ mass fraction decreased and shifted towards the hot oxidizer stream where it peaks after flame front position. The formation of $\mathrm{H}_{2} \mathrm{O}$ indicates termination of the combustion process. Moreover, it can be noticed that when methane volume augments in the mixture, $\mathrm{CO}_{2}$ decreases slowly along the radial direction compared to $\mathrm{CO}$ profiles. After the flame front, shown by maximum temperature, it can be seen that $\mathrm{CO}$ recombines to form $\mathrm{CO}_{2}$.

The NO species is very sensitive to temperature variation, since temperature exhibits a slight decrease with methane volume; then, the NO shows a reduction when methane is added to the mixture, Fig. 11 (a). The maximum NO mass fraction varies from $18 \mathrm{ppm}$ for B00S25 to $15.3 \mathrm{ppm}$ for B50S25.

In Fig. 11 (b), the same species ( $\mathrm{Y}_{\mathrm{CO} 2}, \mathrm{Y}_{\mathrm{H} 2 \mathrm{O}}, \mathrm{Y}_{\mathrm{CO}}$, and $\mathrm{Y}_{\mathrm{NO}}$ ) are presented (cases 7 to 10), when increasing hydrogen volume from $0 \%$ to $50 \%, \mathrm{H}_{2} \mathrm{O}$ mass fraction increases significantly compared to the previous case (BXS25) because its formation depends directly on hydrogen volume. Furthermore, it can be noticed that when the volume of hydrogen increases in the syngas, $\mathrm{CO}_{2}$ decreases slowly along the radial direction compared to $\mathrm{CO}$ profiles. After the flame front, shown by maximum temperature, it can be seen that $\mathrm{CO}$ recombines to form $\mathrm{CO}_{2}$.
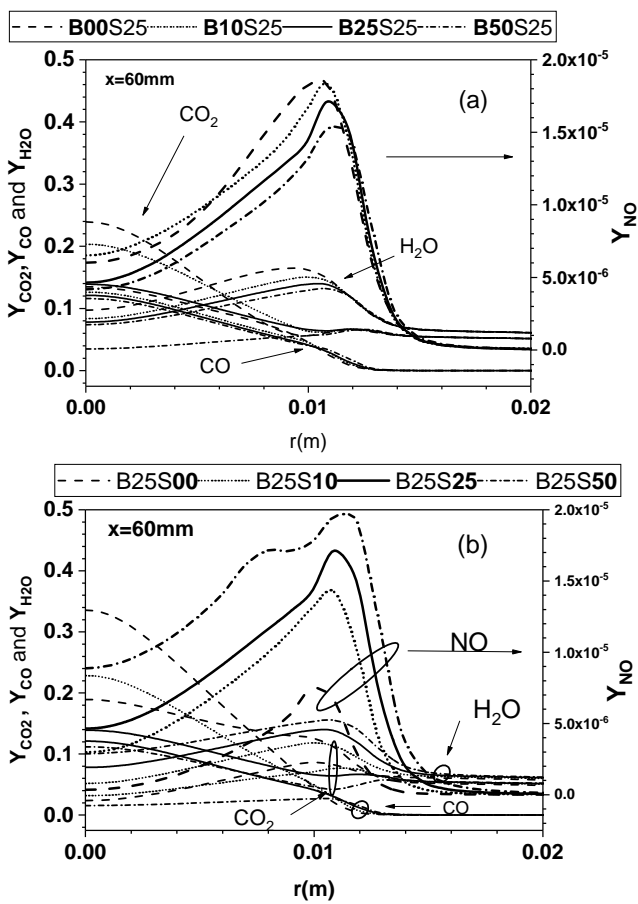

Fig. 11. Radial profile of $Y_{\mathrm{H} 2 \mathrm{O}}, \mathrm{Y}_{\mathrm{CO} 2}, \mathrm{Y}_{\mathrm{CO}}$, and $Y_{\text {NO }}$ at $x=60 \mathrm{~mm}$ for cases 4 to 10 of Table 3.

When hydrogen increases (B25SX), the NO profiles show opposite trends comparatively to BXS25 cases. As said before, NO species is directly linked to temperature variation; consequently, when hydrogen increases in the mixture, NO species increases too. Maximum NO production is recorded for the mixture B25S50 with $19.7 \mathrm{ppm}$ while the minimum values are $7.5 \mathrm{ppm}$ for the $\mathrm{B} 25 \mathrm{~S} 00$ mixture.

To deeply investigate NO formation sources, the Rate Of Production (ROP) of selected reactions in different NO production routes are presented in Fig. 12 ( $a, b$ and $c$ ) for the mean composition B25S25 at section $\mathrm{x}=60 \mathrm{~mm}$. Then axial NO emission index (Takeno and Nishioka 1993)(EINO) is showed. Since the fuel contains a significant volume of hydrogen, it can be seen that the dominant production mechanism is the $\mathrm{NNH}$ route followed by prompt, thermal, and $\mathrm{N}_{2} \mathrm{O}$ intermediate one; these results are consistent with (Gao et al. 2013). The axial variation of the EINO, Fig. 12 (d), clearly confirms this order. From Figs. 12 (a,b, and c), the maximum reaction rate is $42.110^{-5} \mathrm{kmol} / \mathrm{m}^{3} \mathrm{~s}$ for $\mathrm{NNH}$, while maximums of prompt, thermal, and $\mathrm{N}_{2} \mathrm{O}$ 
routes are respectively $2.3410^{-5}, 1.5710^{-5}$, and 2.34 $10^{-5} \mathrm{kmol} / \mathrm{m}^{3} \mathrm{~s}$. In summary, the most significant path is $\mathrm{NNH}$ through $\mathrm{N}_{2} \Rightarrow \mathrm{NNH} \Rightarrow \mathrm{NO}$ (Jiang et al. 2018).K Despite these production paths, it can be observed that NO production is very low compared to conventional combustion Fig. 12 (d), which makes the MILD combustion of biofuels an attractive alternative.
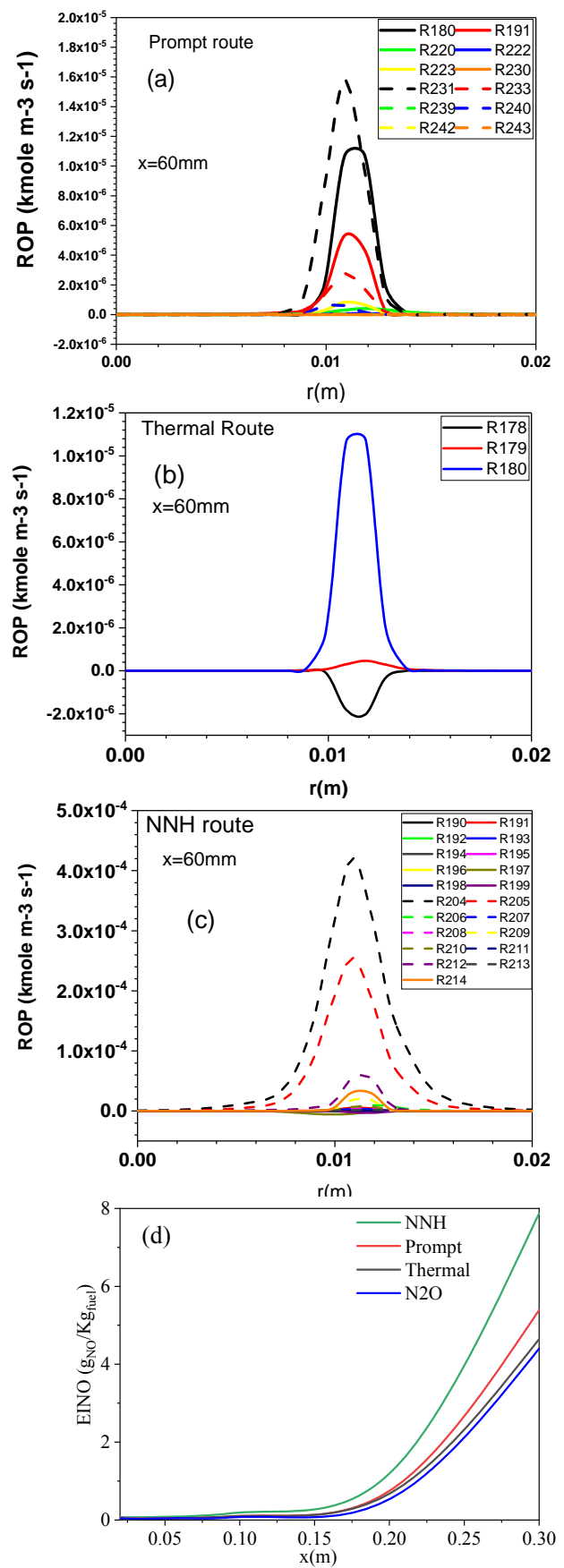

Fig. 12. NO production routes: a), b) and c) Radial profiles of reaction rates at $x=60 \mathrm{~mm}$, and d) Contribution of routes in axial EINO.

\subsection{Effect of co-flow temperature}

Effect of co-flow temperature on the distribution of temperature, $\mathrm{NO}, \mathrm{H}_{2} \mathrm{O}$, and $\mathrm{OH}$ mass fraction is demonstrated for four temperature values (cases 7,11,12, and 13 in table 4). Figure 13 (a) shows temperature and $\mathrm{NO}$ concentration radial profiles at both locations $\mathrm{z}=30 \mathrm{~mm}$ and $60 \mathrm{~mm}$ for the mixture B25S25. It can be observed that temperature peak increases with the augmentation of co-flow temperature.

Table 4 Oxidizer temperature variation.

\begin{tabular}{|c|c|c|}
\hline $\mathrm{N}^{\circ}$ & ID & Oxidizer T(K) \\
\hline 11 & B25S25(1500) & 1500 \\
\hline 12 & B25S25(1700) & 1700 \\
\hline 13 & B25S25(1900) & 1900 \\
\hline
\end{tabular}

Oxidizer: $\mathrm{X}_{\mathrm{O} 2}=0.09, \mathrm{X}_{\mathrm{H} 2 \mathrm{O}}=0.065$,

$\mathrm{X}_{\mathrm{CO} 2}=0.065, \mathrm{X}_{\mathrm{N} 2}=0.79$.

Fuel velocity: $58.75 \mathrm{~m} / \mathrm{s}$

The limits of co-flow injection temperatures are $\mathrm{T}_{\mathrm{cf}}=1300 \mathrm{~K}$, which yields a maximum flame temperature of $1826 \mathrm{~K}$, and $\mathrm{T}_{\mathrm{cf}}=1900 \mathrm{~K}$ which gives $2246 \mathrm{~K}$. Both temperatures are recorded at axial location $\mathrm{x}=60 \mathrm{~mm}$ and radial one $\mathrm{r}=0.011 \mathrm{~m}$. For all injection temperatures, it can be seen that an increase in temperature by combustion didn't exceed mixture autoignition temperature. This prevails the MILD combustion regime at this location.

When the co-flow temperature augments from $1300 \mathrm{~K}$ to $1900 \mathrm{~K}$, the maximum NO mass fraction increases thirteen times from $17.4 \mathrm{ppm}$ to $231 \mathrm{ppm}$. The trend of NO concentration is in line with (Gao et al. 2013) results, where they explained this increase by the enhancement in the chemical reaction that contributes to the formation of both species $\mathrm{NNH}$ and $\mathrm{HCN}$.

Figure 13(b) shows both $\mathrm{H}_{2} \mathrm{O}$ and $\mathrm{OH}$ species mole fraction variation along the radial direction for the mixture $\mathrm{B} 25 \mathrm{~S} 25$ at both locations $\mathrm{x}=30$ and $60 \mathrm{~mm}$, for the different temperatures of co-flow (cases $7,11,12$ and 13 of table.3). Despite values, it can be seen that $\mathrm{H}_{2} \mathrm{O}$ and $\mathrm{OH}$ profiles are similar for both locations and co-flow injection temperatures. The maximum value of $\mathrm{OH}$ is situated at the same position as the temperature peak. Effect of co-flow temperature on $\mathrm{H}_{2} \mathrm{O}$ concentration is not significant, since it is a stable species, while $\mathrm{OH}$ concentration doubles from $2.0310^{-3}$ to $4.6810^{-3}$ while $\mathrm{T}_{\text {cf }}$ ranges from $1300 \mathrm{~K}$ to $1900 \mathrm{~K}$ (at location $\mathrm{x}=60 \mathrm{~mm}$ ).

\subsection{Effect of the fuel jet Reynolds number}

To study the flow dynamics on the flame structure, the fuel jet Reynolds number was varied from 10,000 to 20,000 for mean composition B25S25.

The temperature radial profiles are presented in Fig. 14 for both locations $\mathrm{x}=30$ and $60 \mathrm{~mm}$ for three Reynolds numbers namely: $\mathrm{Re}=10,000.15,000$ and 20,000 . It can be seen that when increasing Reynolds number from 10,000 to 20,000 the temperature was 
O. Benbouaziz et al. / JAFM, Vol. 14, No. 6, pp. 1851-1868, 2021.
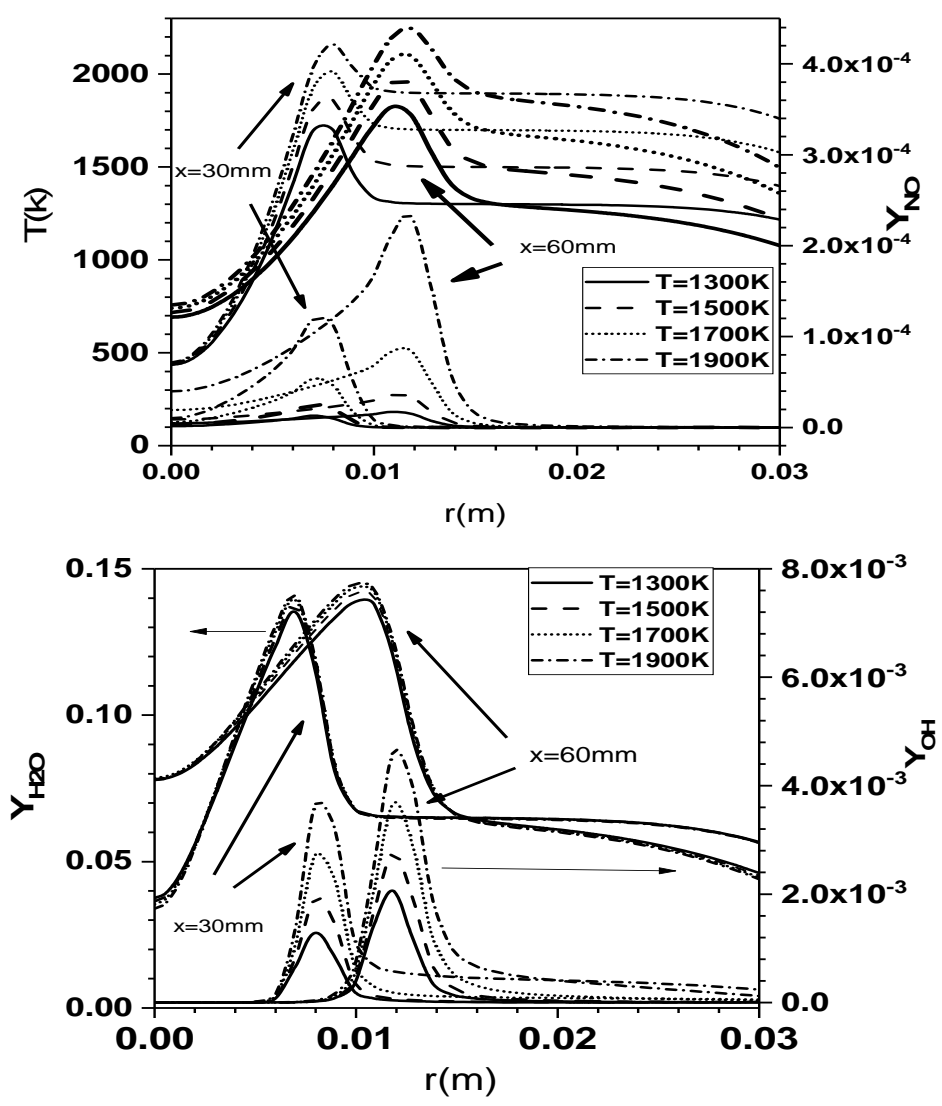

Fig. 13. Radial profiles of temperature, $Y_{\text {No }} Y_{H 20}$, and $Y_{\text {OH }}$ at $x=60 \mathrm{~mm}$ cases $7,11,12$, and 13 of Table 4.

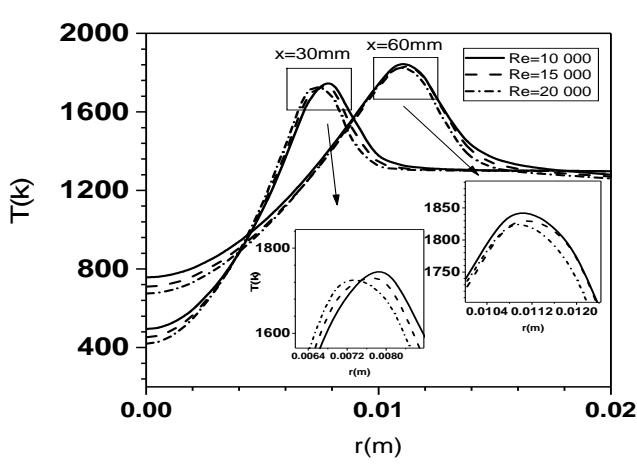

Fig. 14. Radial profiles of temperature at $x=60 \mathrm{~mm}$ for cases 14,15 and 16 of Table 5 .

Table 5 Fuel Reynolds number variation.

\begin{tabular}{|l|l|c|}
\hline $\mathrm{N}^{\circ}$ & ID & Fuel jet Re \\
\hline 14 & B25S25(Re1) & 20,000 \\
\hline 15 & $\mathrm{~B} 25 \mathrm{~S} 25(\mathrm{Re} 2)$ & 15,000 \\
\hline 16 & $\mathrm{~B} 25 \mathrm{~S} 25(\mathrm{Re} 3)$ & 10,000 \\
\hline $\begin{array}{l}\text { Oxidizer: } \\
\mathrm{X}_{\mathrm{O} 2}=0.09, \mathrm{X}_{\mathrm{H} 2 \mathrm{O}}=0.065, \mathrm{X}_{\mathrm{CO} 2}=0.065, \\
\mathrm{X}_{\mathrm{N} 2}=0.79 .\end{array}$ \\
\hline
\end{tabular}

not affected significantly, as the maximum reduction in temperature is $\Delta \mathrm{T}=20 \mathrm{~K}$. This reduction is due to flow residence time which is reduced by increasing Reynolds number. Consequently, chemical time is reduced resulting in unburned species and then reduced temperature.

Figure 15(a) represents the mixture fraction and NO mass fraction for both locations $\mathrm{x}=30 \mathrm{~mm}$ and 60 $\mathrm{mm}$. The mixture fraction increases because additional fuel is injected when the fuel jet Reynolds number is increased. Consequently, the NO species is reduced (Fig. 15(b)) since it is very sensitive to temperature. The same behaviors were reported by (Huang et al. 2014a).

Also, stable species are reduced by incomplete combustion (which is enhanced by Reynolds number); whereas, radical or unburnt species are enhanced. This behavior can be seen in Fig. 15(b) which shows radial profiles of $\mathrm{H}_{2} \mathrm{O}$ and $\mathrm{OH}$.

\subsection{Effect of oxygen concentration}

Figure 16 illustrates the effect of oxygen concentration in hot co-flow on the temperature, $\mathrm{H}_{2} \mathrm{O}, \mathrm{OH}$, and $\mathrm{NO}$ mass fractions at both locations $\mathrm{x}=30$ and $60 \mathrm{~mm}$ for biogas-syngas mixture B25S25. The comparison among four different oxygen levels is conducted (cases 17 to 20 Table 6) with constant velocity $\mathrm{u}=58.75 \mathrm{~m} / \mathrm{s}$ and co-flow temperature of $1300 \mathrm{~K}$. 


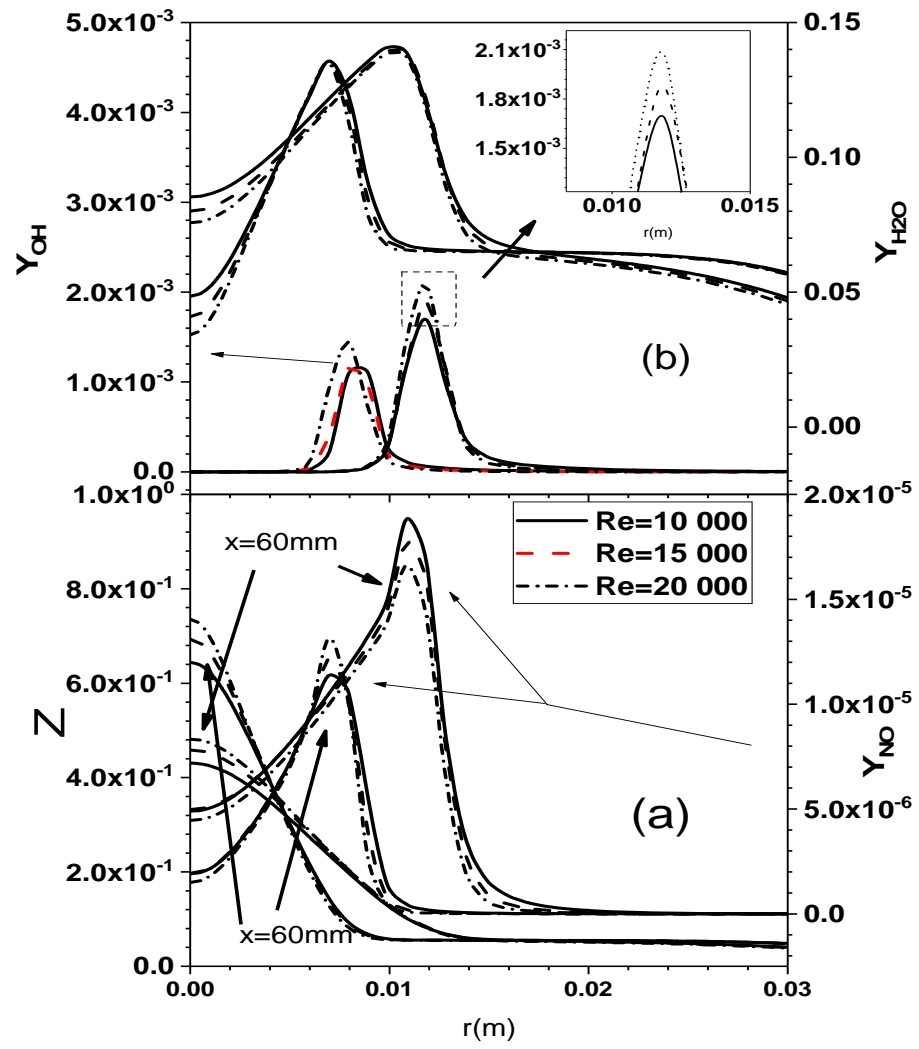

Fig. 15. (a) Radial profiles of $z$ and $Y_{\mathrm{NO}}$, (b) $Y_{\text {он }}$ and $Y_{\mathrm{H} 2 \mathrm{O}}$ at $x=60 \mathrm{~mm}$ for cases 14,15 , and 16 of Table 5 .
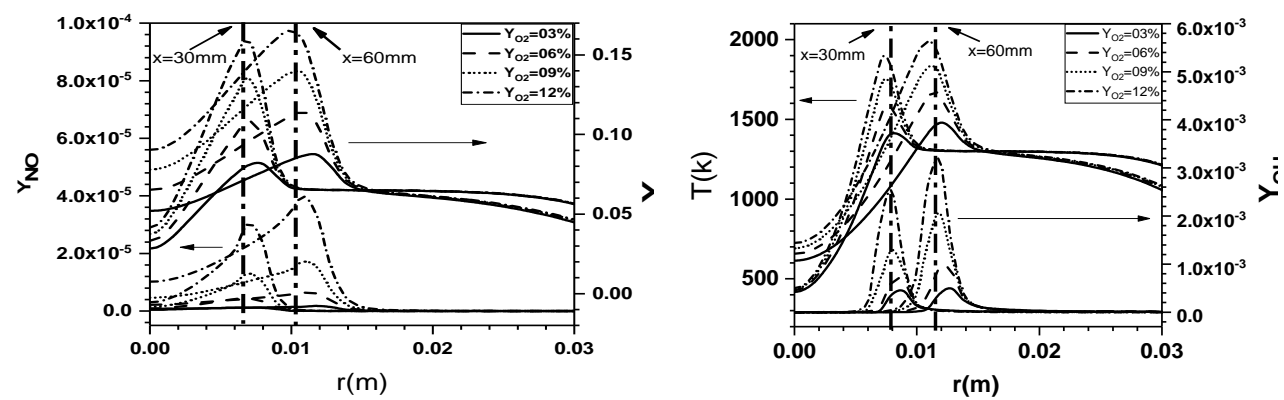

Fig. 16. Radial profiles of temperature, $Y_{\text {NO}}, Y_{H 2 O}$, and $Y_{H 2 O}$ at $x=60 \mathrm{~mm}$ for cases 17 to 20 of Table 6 .

Table 6 Oxygen volume in oxidizer.

\begin{tabular}{|c|c|c|c|}
\hline $\mathrm{N}^{\circ}$ & ID & $\mathrm{O}_{2}$ vol. $\%$ & $\mathrm{~N}_{2}$ vol. $\%$ \\
\hline 17 & $\mathrm{~B} 25 \mathrm{~S} 25(\mathrm{Ox} 3)$ & 3 & 85 \\
\hline 18 & $\mathrm{~B} 25 \mathrm{~S} 25(\mathrm{Ox} 6)$ & 6 & 82 \\
\hline 19 & $\mathrm{~B} 25 \mathrm{~S} 25(\mathrm{Ox} 9)$ & 9 & 79 \\
\hline 20 & $\mathrm{~B} 25 \mathrm{~S} 25(\mathrm{Ox} 12)$ & 12 & 76 \\
\hline \multicolumn{4}{|c|}{ Oxidizer: $\mathrm{X}_{\mathrm{H} 2 \mathrm{O}}=0.065, \mathrm{X}_{\mathrm{CO} 2}=0.065$. } \\
\hline
\end{tabular}

It can be seen from Fig.16 (a) that temperature and $\mathrm{OH}$ mass fraction is significantly increased by oxygen concentration augmentation in the oxidizer stream. For each oxygen volume, temperature and $\mathrm{OH}$ profiles share the same peak positions. Oxygen increase shifts slightly maximums of temperature and $\mathrm{OH}$ to the fuel jet side since local equivalence ratio has decreased with oxygen addition. From Fig. 16 (b), as said before, the NO species is linked to temperature level, which explains the significant increase of NO mass fraction with oxygen. The NO mass fraction maximum increases from $8.5 \mathrm{ppm}$ for $3 \%$ of oxygen in oxidizer to $40 \mathrm{ppm}$ for $12 \%$ of 
oxygen volume. Furthermore, $\mathrm{H}_{2} \mathrm{O}$ mass fraction is highly increased by oxygen volume in the oxidizer stream. In MILD combustion, the lack of oxygen reduces temperature and complete combustion species; whereas, it enhances unburnt species. Oxygen addition enhances temperature and complete combustion products such as $\mathrm{H}_{2} \mathrm{O}$ and $\mathrm{CO}_{2}$.

\section{CONCLUSIONS}

In this study, turbulent MILD combustion of the biogas-syngas mixture has been investigated numerically. The JHC burner configuration was adopted. Effects of mixture composition, hot co-flow temperature, fuel jet Reynolds number, and oxygen concentration on the structure of the flame and emissions were considered. The RANS approach in conjunction with the EDC combustion model and detailed kinetic mechanisms were used in the simulation. The main conclusions that can be drawn are:

1. The temperature augmentation is more significant when hydrogen volume increases in the fuel mixture, on the other hand, methane addition has a negligible effect. Moreover, both methane and hydrogen addition improve autoignition.

2. Methane addition to the mixture increases flame volume, which can be beneficial for processes involving flame radiation. Whereas, hydrogen addition increases mixture reactivity and local flame speed which fixes flame liftoff issues.

3. Coflow temperature augmentation preserves the MILD combustion regime but produces more NO emissions. On the other hand, fuel injection Reynolds number increase reduces slightly temperature and significantly $\mathrm{NO}$ emissions.

4. The NO production shows a reduction when methane is added to the biogas; whereas, it increases with hydrogen augmentation in syngas.

5. The dominant NO production mechanism is $\mathrm{NNH}$ followed by prompt, thermal, and $\mathrm{N}_{2} \mathrm{O}$ intermediate ones. $\mathrm{NNH}$ and $\mathrm{N}_{2} \mathrm{O}$ paths are enabled in a hot and less rich region whereas the prompt route is activated in the relatively cold and rich zone.

\section{REFERENCES}

Aminian, J., C. Galletti, S. Shahhosseini and L. Tognotti (2011). Key modeling issues in prediction of minor species in dilutedpreheated combustion conditions. Applied Thermal Engineering 31(16), 3287-3300.

Aminian, Javad, Galletti, C., S. Shahhosseini and L. Tognotti (2012). Numerical investigation of a MILD combustion burner: Analysis of mixing field, chemical kinetics and turbulence-chemistry interaction. Flow, Turbulence and Combustion 88(4), 597-623.
Benini, E., S. Pandolfo and S. Zoppellari (2009). Reduction of NO emissions in a turbojet combustor by direct water/steam injection: Numerical and experimental assessment. Applied Thermal Engineering 29(17-18), 3506-3510.

Bilger, R. W. and S. H. Stårner, R. J. Kee (2006). On reduced mechanisms for methane $\cdot$ air combustion in nonpremixed flames. Combustion and Flame 1990, 80(2), 135-149.

Boussetla, S., A. Mameri and A. Hadef (2021). NO emission from non-premixed MILD combustion of biogas-syngas mixtures in opposed jet configuration. International Journal of Hydrogen Energy 2021..

Bowman, C. T., R. K. Hanson, D. F. Davidson, W. C. Gardiner Jr, V. Lissianski, G. P. Smith, D. M. Golden, M. Frenklach and M. Goldenberg (1995). GRI-Mech 2.11, 1995. URL Http://Www. Me. Berkeley. Edu/Gri_mech.

Caudal, J. (2013) Simulation numérique du reformage autothermique du méthane(Ph.D. thesis) Ecole Centrale Paris, $\langle$ NNT : 2013ECAP0020 $\rangle$.

Cavaliere, A. and M. de Joannon (2004). Mild combustion. Progress in Energy and Combustion Science 30(4), 329-366.

Chandra, R., V. K. Vijay, P. M. V. Subbarao and T. K. Khura (2011). Performance evaluation of a constant speed IC engine on CNG, methane enriched biogas and biogas. Applied Energy 88(11), 3969-3977.

Chefurka, P. (2007). World energy and population, [Online]. Available AT http://www. paulchefurka.ca/WEAP2/WEAP2.html. Accessed: May. 07, 2021.

Chinnici, A., G. J. Nathan and B. B. Dally (2020). Experimental and numerical study of the influence of syngas composition on the performance and stability of a laboratoryscale MILD combustor. Experimental Thermal and Fluid Science 115(October 2019), 110083.

Christo, F. C. and B. B. Dally (2005). Modeling turbulent reacting jets issuing into a hot and diluted coflow. Combustion and Flame 142(1-2), 117-129.

Colorado, A. F., B. A. Herrera and A. A. Amell (2010). Performance of a Flameless combustion furnace using biogas and natural gas. Bioresource Technology 101(7), 24432449.

Dai, C., Z. Shu, P. Li and J. Mi (2018). Combustion Characteristics of a Methane Jet Flame in Hot Oxidant Coflow Diluted by $\mathrm{H} 2 \mathrm{O}$ versus the Case by N2. Energy and Fuels 32(1), 875888 .

Dally, B. B., A. N. Karpetis and R. S. Barlow (2002). Structure of turbulent non-premixed 
O. Benbouaziz et al. / JAFM, Vol. 14, No. 6, pp. 1851-1868, 2021.

jet flames in a diluted hot coflow. Proceedings of the Combustion Institute 29(1), 1147-1154.

Demirbas, A. (2009). Political, economic and environmental impacts of biofuels: A review. Applied Energy 86, S108-S117.

Frassoldati, A., P. Sharma, A. Cuoci, T. Faravelli and E. Ranzi (2010). Kinetic and fluid dynamics modeling of methane/hydrogen jet flames in diluted coflow. Applied Thermal Engineering 30(4), 376-383.

Galletti, C., A. Parente, M. Derudi, R. Rota and L. Tognotti (2009). Numerical and experimental analysis of NO emissions from a lab-scale burner fed with hydrogen-enriched fuels and operating in MILD combustion. International Journal of Hydrogen Energy 34(19), 83398351.

Galletti, C., A. Parente and L. Tognotti (2007). Numerical and experimental investigation of a mild combustion burner. Combustion and Flame 151(4), 649-664.

Gao, X., F. Duan, S. C. Lim and M. S. Yip (2013). NOx formation in hydrogen-methane turbulent diffusion flame under the moderate or intense low-oxygen dilution conditions. Energy 59, 559-569.

Gordon, R. L., A. R. Masri and E. Mastorakos (2009). Heat release rate as represented by $[\mathrm{OH}] \times[\mathrm{CH} 2 \mathrm{O}]$ and its role in autoignition. Combustion Theory and Modelling 13(4), 645-670.

Gupta, A. K. (2000). Flame characteristics with high temperature air combustion, AIAA 2000593. 38th Aerospace Sciences Meeting and Exhibit. January 2000.

Holm-Nielsen, J. B., T. Al Seadi and O. P. Popiel (2009). The future of anaerobic digestion and biogas utilization. Bioresource Technology 100(22), 5478-5484.

Hosseini, S. E., G. Bagheri, M. Abdul Wahid and A. Saat (2015). Clean Fuel, Clean Energy Conversion Technology: Experimental and Numerical Investigation of Palm Oil Mill Effluent Biogas Flameless Combustion. BioResources 10(4), 6597-6609.

Hosseini, S. E. and M. A. Wahid (2013). Biogas utilization: Experimental investigation on biogas flameless combustion in lab-scale furnace. Energy Conversion and Management 74, 426-432.

Huang, M. M., W. W. Shao, Y. Xiong, Y. Liu, Z. D. Zhang, F. L. Lei and Y. H. Xiao (2014a). Effect of fuel injection velocity on MILD combustion of syngas in axially-staged combustor. Applied Thermal Engineering 66(1-2), 485-492.

Huang, M., Z. Zhang, W. Shao, Y. Xiong, F. Lei and Y. Xiao (2014b). MILD combustion for hydrogen and syngas at elevated pressures.
Journal of Thermal Science 23(1), 96-102.

Ito, Y., A. K. Gupta, K. Yoshikawa and N. Shimo (2002). Combustion characteristics of low calorific value gas with high temperature and low-oxygen concentration air. Proceedings of the 5th High Temperature Air Combustion and Gasification Conference.

Jiang, X., P. Li, J. Guo, F. Hu, F. Wang, J. Mi and Z. Liu (2018). Detailed investigation of NO mechanism in non-premixed oxy-fuel jet flames with $\mathrm{CH} 4 / \mathrm{H} 2$ fuel blends. International Journal of Hydrogen Energy, 43(17), 8534-8557.

Kaiser, J. F. (1990). On a simple algorithm to calculate the'energy'of a signal. International Conference on Acoustics, Speech, and Signal Processing, 381-384.

Katsuki, M. and T. Hasegawa (1998). The science and technology of combustion in highly preheated air. Symposium (International) on Combustion, 27(2), 3135-3146.

Kazakov, A. and M. Frenklach (1994). Reduced reaction sets based on GRI-Mech 1.2. University of California at Berkeley, Berkeley, CA, Http://Www. Me. Berkeley. Edu/Drm.

Kim, S. H., K. Y. Huh and B. Dally (2005). Conditional moment closure modeling of turbulent nonpremixed combustion in diluted hot coflow. Proceedings of the Combustion Institute 30(1), 751-757.

Lee, I. B., I. S. Woo and M. C. Lee (2016). Effects of nitrogen dilution on the $\mathrm{NOx}$ and $\mathrm{CO}$ emission of $\mathrm{H} 2 / \mathrm{CO} / \mathrm{CH} 4$ syngases in a partially-premixed gas turbine model combustor. International Journal of Hydrogen Energy 41(35), 15841-15851.

Lenzen, M. (2008). Life cycle energy and greenhouse gas emissions of nuclear energy: A review. Energy Conversion and Management 49(8), 2178-2199.

Leung, T. and I. Wierzba (2008). The effect of hydrogen addition on biogas non-premixed jet flame stability in a co-flowing air stream. International Journal of Hydrogen Energy 33(14), 3856-3862.

Lewandowski, M. T. and I. S. Ertesvåg (2018a). Analysis of the Eddy Dissipation Concept formulation for MILD combustion modelling. Fuel 224(April 2017), 687-700.

Lewandowski, M. T., Z. Li, A. Parente and J. Pozorski (2020b). Generalised Eddy Dissipation Concept for MILD combustion regime at low local Reynolds and Damköhler numbers. Part 2: Validation of the model. Fuel, 278(February).

Lewandowski, M. T., A. Parente and J. Pozorski (2020c). Generalised Eddy Dissipation Concept for MILD combustion regime at low 
O. Benbouaziz et al. / JAFM, Vol. 14, No. 6, pp. 1851-1868, 2021.

local Reynolds and Damköhler numbers. Part 1: Model framework development. Fuel, 278(July 2019), 117743.

Magnussen, B. (1981). On the structure of turbulence and a generalized eddy dissipation concept for chemical reaction in turbulent flow. 19th Aerospace Sciences Meeting 42.

Mahmoudi, Y., G. Sarras, L. D. A. Mendez and M. J. Tummers (2013). Flame Structure and Stabilization Mechanism of Biogas Flame in a Jet-in-Hot-Coflow Burner In Selcuk N, Beretta F, Mansour MH, d'Anna A, editors, Proceedings of the 8th Mediterranean Combustion Symposium. Ankara, Turkey: International Centre For Heat and Mass Transfer, METU 1-12

Mameri, A., S. Boussetla, R. Belalmi and Z. Aouachria (2019). Combustion characterization of the mixtures biogassyngas, strain rate and ambient pressure effects. International Journal of Hydrogen Energy 44(39), 22478-22491.

Mameri, A., F. Tabet and A. Hadef (2018). MILD combustion of hydrogenated biogas under several operating conditions in an opposed jet configuration. International Journal of Hydrogen Energy 43(6), 3566-3576.

Mardani, A. and H. Karimi Motaalegh Mahalegi (2019). Hydrogen enrichment of methane and syngas for MILD combustion. International Journal of Hydrogen Energy 44(18), 94239437.

Mardani, A. and S. Tabejamaat (2010). Effect of hydrogen on hydrogen-methane turbulent non-premixed flame under MILD condition. International Journal of Hydrogen Energy 35(20), 11324-11331.

Mardani, A., S. Tabejamaat and M. Ghamari (2010). Numerical study of influence of molecular diffusion in the Mild combustion regime. Combustion Theory and Modelling 14(5), 747-774.

Maschio, G., A. Lucchesi and G. Stoppato (1994). Production of syngas from biomass. Bioresource Technology 48(2), 119-126.

Menter, F. R. (1994). Two-equation eddy-viscosity turbulence models for engineering applications. AIAA Journal 32(8), 1598-1605.

Mörtberg, M., W. Blasiak and A. K. Gupta (2007). Experimental investigation of flow phenomena of a single fuel jet in cross-flow during highly preheated air combustion conditions 2007.

Niioka, T. (1999). Fundamentals and applications of high-temperature air combustion. https://www.osti.gov/biblio/20019064

Niioka, T. (2005). Impact of knowledge gained from the HiCOT Project on development of combustors. Proceedings, 1-4.
Parente, A., M. R. Malik, F. Contino, A. Cuoci and B. B. Dally (2016). Extension of the Eddy Dissipation Concept for turbulence/chemistry interactions to MILD combustion. Fuel 163, 98-111.

Park, J., D. Hwang, J. Choi, K. Lee, S. Keel and S. Shim (2003). Chemical effects of $\mathrm{CO} 2$ addition to oxidizer and fuel streams on flame structure in $\mathrm{H} 2-\mathrm{O} 2$ counterflow diffusion flames. International Journal of Energy Research 27(13), 1205-1220.

Sabia, P., G. Sorrentino, P. Bozza, G. Ceriello, R. Ragucci and M. De Joannon (2019). Fuel and thermal load flexibility of a MILD burner. Proceedings of the Combustion Institute, 37(4), 4547-4554

Saha, M., G. Gitto, A. Chinnici and B. B. Dally (2017). Comparative study of the MILD combustion characteristics of biomass and brown coal. Energy and Fuels 32(4), 42024211.

Sahin, M. (2019). Combustion characteristics of various biogas flames under reduced oxygen concentration conditions. Energy Sources, Part A: Recovery, Utilization and Environmental Effects 41(19), 2415-2427.

Shabanian, S. R., M. Derudi, M. Rahimi, A. Frassoldati, A. Cuoci and T. Faravelli (2011). Experimental and numerical analysis of syngas MILD combustion. Conference Poster 3400(2007), 1-7.

Shih, T. H., W. W. Liou, A. Shabbir, Z. Yang and J. Zhu (1994). A new k-epsilon eddy viscosity model for high Reynolds number turbulent flows: Model development and validation. Computers and Fluids, Volume 24, Issue 3, 1995, Pages 227-238, ISSN 0045-7930.

Smith, G. P. (1999). GRI-Mech 3.0. Http://Www. Me. Berkley. Edu/Gri mech/.

Solangi, K. H., M. R. Islam, R. Saidur, N. A. Rahim and H. Fayaz (2011). A review on global solar energy policy. Renewable and Sustainable Energy Reviews 15(4), 2149-2163.

Spalding, D. B. (1977). Development of the eddybreak-up model of turbulent combustion. Symposium (International) on Combustion 16(1), 1657-1663.

Taimoor, A. A., A. Muhammad and W. Saleem (2016). Humidified exhaust recirculation for efficient combined cycle gas turbines. Energy 106, 356-366.

Takeno, T. and M. Nishioka (1993). Species conservation and emission indices for flames described by similarity solutions. Combustion and Flame 92(4), 465-468.

Turns, S. R. (1996). Introduction to combustion (Vol. 287). McGraw-Hill Companies.

Vasavan, A., P. De Goey and J. Van Oijen (2018). Numerical Study on the Autoignition of 
O. Benbouaziz et al. / JAFM, Vol. 14, No. 6, pp. 1851-1868, 2021.

Biogas in Moderate or Intense Low Oxygen Dilution Nonpremixed Combustion Systems. Energy and Fuels 32(8), 8768-8780.

Verma, Kr., P., L. Saxena and R. Gupta (2016). Biogas: Its Application and Production. Innovation The Research Concept 1(9), 26 28 .

Wang, F., P. Li, J. Mi, J. Wang and M. Xu (2015a). Chemical kinetic effect of hydrogen addition on ethylene jet flames in a hot and diluted coflow. International Journal of Hydrogen Energy 40(46), 16634-16648.

Wang, F., P. Li, J. Zhang, Z. Mei, J. Mi and J. Wang (2015b). Routes of formation and destruction of nitrogen oxides in $\mathrm{CH} 4 / \mathrm{H} 2$ jet flames in a hot coflow. International Journal of Hydrogen Energy 40(18), 6228-6242.

Wang, F., J. Mi, P. Li and C. Zheng (2011c). Diffusion flame of a $\mathrm{CH} 4 / \mathrm{H} 2$ jet in hot lowoxygen coflow. International Journal of
Hydrogen Energy 36(15), 9267-9277.

Wunning, J. G. (2000). Flameless combustion in the thermal process technology. Second International Seminar on High Temperature Combustion, Stockholm, Sweden, 17-18.

Zhang, J., J. Mi, P. Li, F. Wang and B. B. Dally (2015). Moderate or intense low-oxygen dilution combustion of methane diluted by CO2 and N2. Energy and Fuels 29(7), 45764585.

Zhen, H. S., C. W. Leung and C. S. Cheung (2013). Effects of hydrogen addition on the characteristics of a biogas diffusion flame. International Journal of Hydrogen Energy 38(16), 6874-6881.

Zouagri, R., A. Mameri, F. Tabet and A. Hadef (2020). Characterization of the combustion of the mixtures biogas-syngas at high strain rates. Fuel 271(February). 